\title{
Pterostilbene Inhibits the Growth of Human Esophageal Cancer Cells by Regulating Endoplasmic Reticulum Stress
}

\author{
Yingtong Feng ${ }^{\mathrm{a}, \mathrm{c}}$ Yang Yang ${ }^{\mathrm{b}}$ Chongxi Fan ${ }^{\mathrm{a}}$ Shouyin Dia Wei Hu $\mathrm{Hu}^{\mathrm{b}}$ Shuai Jiang ${ }^{\mathrm{d}}$ \\ Tian Li $^{b}$ Zhiqiang Ma ${ }^{a}$ Deng Chao ${ }^{e}$ Xiao Fenge Zhenlong Xin ${ }^{b}$ Sainan Pang ${ }^{f}$ \\ Xiaofei Li ${ }^{a}$ Xiaolong Yan ${ }^{a}$ \\ aDepartment of Thoracic Surgery, Tangdu Hospital, The Fourth Military Medical University, Xi'an, \\ bDepartment of Biomedical Engineering, The Fourth Military Medical University, Xi'an, 'Department of \\ Cardiothoracic Surgery, the 97th Hospital of PLA, Xuzhou, dDepartment of Aerospace Medicine, The \\ Fourth Military Medical University, Xi'an, eDepartment of Cardiovascular Surgery, Xijing Hospital, The \\ Fourth Military Medical University, Xi'an, 'Department of Cardiothoracic Surgery, The First Affiliated \\ Hospital, Jiamusi University, Jiamusi, China
}

\section{Key Words}

Pterostilbene • Endoplasmic reticulum stress $•$ Human esophageal cancer cells $\bullet$ CHOP siRNA - Thapsigargin

\begin{abstract}
Background/Aims: Pterostilbene (PTE), a natural dimethylated resveratrol analog from blueberries, is known to have diverse pharmacological activities, including anticancer properties. In this study, we investigated the anticancer activity of PTE against human esophageal cancer cells both in vitro and in vivo and explored the role of endoplasmic reticulum (ER) stress (ERS) signaling in this process. Methods: Cell viability, the apoptotic index, Caspase 3 activity, adhesion, migration, reactive oxygen species (ROS) levels, and glutathione (GSH) levels were detected to explore the effect of PTE on human EC109 esophageal cancer cells. Furthermore, SiRNA transfection and a chemical inhibitor were employed to confirm the role of ERS. Results: PTE treatment dose- and time-dependently decreased the viability of human esophageal cancer EC109 cells. PTE also decreased tumor cell adhesion, migration and intracellular GSH levels while increasing the apoptotic index, Caspase 3 activity and ROS levels, which suggest the strong anticancer activity of PTE. Furthermore, PTE treatment increased the expression of ERS-related molecules (GRP78, ATF6, p-PERK, p-eIF2 $\alpha$ and CHOP), upregulated the proapoptosis-related protein PUMA and downregulated the anti-apoptosis-related protein $\mathrm{BCl}-2$ while promoting the translocation of cytochrome $c$ from mitochondria to cytosol and the activation of Caspase 9 and Caspase 12. The downregulation of ERS signaling by CHOP siRNA desensitized esophageal cancer cells to PTE treatment, whereas upregulation of ERS signaling by thapsigargin (THA) had the opposite effect. N-Acetylcysteine (NAC), a ROS scavenger,

Y. Feng, Y. Yang and C. Fan contributed equally to this work.

Xiaolong Yan MD, PhD and Xiaofei Li MD, PhD

Department of Thoracic Surgery, Tangdu Hospital, The Fourth Military Medical University, 1 Xinsi Road, Xi'an 710038, (China)

Tel. +862984777436, E-Mail xiaolongyanfmmu@126.com, E-Mail xiaofeilitangdu@126.com
\end{abstract}

KARGER 


\section{Cellular Physiology Cell Physiol Biochem 2016;38:1226-1244

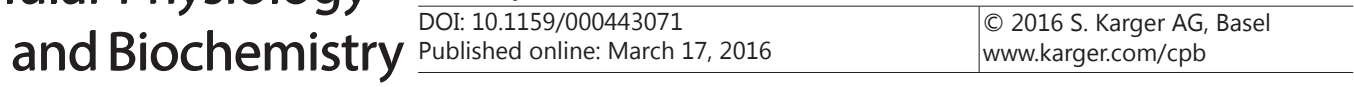 \\ Feng et al.: PTE Inhibits Esophageal Cancer via ERS}

also desensitized esophageal cancer cells to PTE treatment. Conclusions: Overall, the results indicate that PTE is a potent anti-cancer pharmaceutical against human esophageal cancer, and the possible mechanism involves the activation of ERS signaling pathways.

Copyright $@ 2016$ S. Karger AG, Basel

\section{Introduction}

Esophageal cancer, which principally consists of esophageal squamous cell carcinoma and esophageal adenocarcinoma, is one of the leading causes of cancer-related death [1], and the incidence is increasing every year. Despite the development of novel targeting agents and various therapeutic combinations, there is no cure for advanced cancer. Accordingly, there is an urgent need to develop novel therapeutic agents, specifically chemopreventive agents generated from natural materials with few harmful effects [2].

Pterostilbene (3, 5-dimethoxy-4'-hydroxystilbene, 4'-[(1E)-2-(3,5-dimethoxyphenyl) ethenyl]phenol, PTE), a natural dimethylated resveratrol analog from blueberries, has diverse pharmacological activities and demonstrates anticancer activity [3], as well as low toxicity [4], in lung cancer [5], leukemia [6], breast cancer [7] and prostate cancer [8]. Because of its greater lipophilicity due to hydroxyl group substitution with methoxyl groups, PTE shows greater bioavailability than resveratrol and is therefore more potent [9]. However, the effects of PTE on human esophageal cancer and the possible mechanisms have not yet been elucidated.

Endoplasmic reticulum (ER) stress (ERS) is caused by disturbances in the structure and function of the ER and can result from hypoxia, nutrient deprivation, $\mathrm{Ca}^{2+}$ imbalance and protein glycosylation perturbation $[10,11]$. ERS leads to the accumulation of misfolded and unfolded proteins in the ER and activation of the unfolded protein response (UPR) pathway. The UPR pathway is triggered through three sensors: activating transcription factor 6 (ATF6), PKR-like ER kinase (PERK) and inositol-requiring enzyme 1 (IRE1) [10-12]. Without ERS, these sensors are inactivated by the binding of chaperone glucose-regulated protein 78 (GRP78). However, upon ERS, misfolded and unfolded proteins bind to GRP78, releasing it from the UPR sensors. Finally, UPR is triggered by the transcription of genes encoding proteins involved in this process, reducing global protein synthesis. These activities restore normal ER function, the failure of which induces apoptosis [10,13].

Apoptosis, which is essential for normal tissue development, is controlled by complex regulatory networks. Indeed, the deregulation of apoptosis contributes to pathologic disorders such as cancer and disrupts the tumor cell-killing effect [14]. The mitochondrial pathway is a major signaling cascade for triggering cell apoptosis via activation of caspases and cleavage of specific cellular substrates [15], and a previous study showed that this pathway predominates in apoptosis through ERS [16]. Additionally, the Bcl-2 family plays a crucial role in apoptotic processes in various cancer cells [17]. Signaling through the PERK, IRE1 and ATF6 pathways can trigger pro-apoptotic signals through the activation of downstream molecules such as C/EBP homologous protein (CHOP), $\alpha$-subunit of eukaryotic translational initiation factor 2 (eIF2 $\alpha$ ) and Bcl-2 family members [18, 19]. P53 upregulated modulator of apoptosis (PUMA) and Bcl-2 are respectively a pro-apoptosis-related and an anti-apoptosis-related member of the Bcl-2 family, and the activation of ERS can affect these two molecules to ultimately regulate apoptosis [20]. Importantly, resveratrol has been demonstrated to induce apoptosis in various cancer cells via regulation of ERS signaling [18, 21], yet the role of ERS signaling in the anticancer activity of PTE has not been examined. In the present study, we assessed the anticancer activity of PTE in human esophageal cancer cells and explored the possible role of ERS signaling. 


\section{Cellular Physiology Cell Physiol Biochem 2016;38:1226-1244 \begin{tabular}{l|l|l} 
DOI: 10.1159/000443071 & (C) 2016 S. Karger AG, Basel
\end{tabular} \begin{tabular}{l|l|l|l|l|l|l} 
and Biochemistry Published online: March 17, 2016 & www.karger.com/cpb \\
\cline { 1 - 2 }
\end{tabular} \\ Feng et al.: PTE Inhibits Esophageal Cancer via ERS}

\section{Materials and Methods}

\section{Materials}

Thapsigargin (THA, ERS inducer), dimethyl sulfoxide (DMSO), 3-(4, 5-dimethylthiazol-2-yl)-2, 5-diphenyltetrazolium bromide (MTT), 2', 7'-dichlorofluorescein diacetate (DCFH-DA), N-acetylcysteine (NAC), and crystal violet were purchased from the Sigma-Aldrich Company (St. Louis, MO, USA). PTE, CHOP siRNA, and antibodies against GRP78, ATF6, CHOP, and cytochrome c were obtained from Santa Cruz Biotechnology (Santa Cruz, CA, USA). Antibodies against phosphorylated-PERK (p-PERK), p-eIF2 $\alpha$, Bcl2, PUMA, Caspase 9, Caspase 12, and $\beta$-actin were obtained from Cell Signaling Technology (Beverly, MA, USA). An antibody against Sp-1 was obtained from Abcam (Cambridge, MA, USA). Calcium green-1-AM was purchased from Molecular Probes, Inc. (Eugene, OR, USA). The Caspase 3 Cellular Activity Assay kit was purchased from Merck (MBL International Corporation, Nagoya, Japan), Cell Counting Kit-8 was purchased from Dojindo (Kumamoto, Japan), and fluorescein isothiocyanate (FITC)-Annexin V/propidium iodide (PI) staining and Bradford protein assay kits were purchased from Beyotime Institute of Biotechnology (Nanjing, Jiangsu, China). Glutathione (GSH) was obtained from Nanjing Jiancheng Bioengineering Institute (Nanjing, Jiangsu, China). Rabbit anti-goat, goat anti-rabbit and goat anti-mouse secondary antibodies were purchased from Zhongshan Company (Beijing, China). Transwell chambers were purchased from Corning (Tewksbury, MA, USA). Matrigel was purchased from BD Biosciences (San Jose, CA, USA).

\section{Cell culture and treatments}

Human EC109 and TE1 esophageal cancer cells were obtained from Cell Culture Center, Chinese Academy of Medical Sciences (Shanghai, China). The cells were grown in Dulbecco's modified Eagle's medium (Gibco, Grand Island, NY, USA) supplemented with 10\% fetal bovine serum (Gibco), L-glutamine (2 mM), penicillin (100 units/ml), streptomycin (100 units/ml) and HEPES $(25 \mathrm{mM})$. The cells were maintained in the presence of $5 \% \mathrm{CO}_{2}$ at $37^{\circ} \mathrm{C}$. A PTE stock solution was prepared in DMSO and diluted with culture medium immediately prior to use; DMSO $(0.1 \%)$ was used as the control. Cells were first treated with PTE $(50,100$ or $150 \mu \mathrm{M})$ and then with PTE $(100 \mu \mathrm{M})$ in the absence or presence of THA $(1 \mu \mathrm{M})$ and CHOP siRNA (pretreated for $24 \mathrm{~h}$ ) for different lengths of time. Where indicated, NAC $(10 \mathrm{mM})$ was applied for $1 \mathrm{~h}$ followed by PTE $(100 \mu \mathrm{M})$ treatment for $24 \mathrm{~h}$. After these treatments were performed, the cells were harvested for further analysis.

Analysis of cell viability

Cell Counting Kit-8 (CCK-8) was used to measure cell viability according to the manufacturer's directions. Briefly, cells were cultured in a 96-well plate and exposed to various treatments. The control group was treated with $0.1 \%$ DMSO. Then, $10 \mu \mathrm{l}$ of CCK- 8 was added to each well, and the plate was incubated at $37^{\circ} \mathrm{C}$ for $2 \mathrm{~h}$. Optical density (OD) values at $450 \mathrm{~nm}$ were measured using a microplate reader (SpectraMax 190, Molecular Device, USA), and cell viability is expressed in terms of the OD value. In addition, the cell morphology was observed under an inverted/phase contrast microscope, and images were taken using a BX61 camera (Olympus Company, Osaka, Japan). All experiments were repeated three times.

Analysis of cell apoptosis

Annexin V/PI staining was used to quantify the effect of PTE on apoptosis using an Annexin V-FITC Apoptosis Detection kit. Briefly, cells were cultured overnight in 6-well plates and then exposed to various treatments. After washing with ice-cold PBS, the cells were detached using trypsin and centrifuged (5 $\mathrm{min}, 4^{\circ} \mathrm{C}, 2000 \mathrm{rpm}$ ) followed by resuspension in $200 \mu \mathrm{l}$ of PBS. The cells were centrifuged again and resuspended in $200 \mu \mathrm{l}$ of $1 \times$ Annexin binding buffer. The cells were then incubated with Annexin V-FITC $(2.5 \mu \mathrm{l})$ and propidium iodide $(5 \mu \mathrm{l})$ for $15 \mathrm{~min}$ at room temperature, and the samples were analyzed for apoptosis using a FACScan flow cytometer equipped with the FACStation data management system and Cell Quest software (all from Becton Dickinson, San Jose, CA, USA).

Analyses of cell adhesion, migration, and invasion

In our preliminary experiment, we found that PTE treatment (at concentrations less than $15 \mu \mathrm{M}$ ) for $24 \mathrm{~h}$ had no effect on EC109 cell proliferation (Fig. 1). Therefore, we performed adhesion and migration assays after $24 \mathrm{~h}$ of PTE treatment $(5,10$ or $15 \mu \mathrm{M})$, as previously described [2]. After treatment with PTE, the cells were centrifuged and re-suspended in basal medium containing $10 \%$ fetal bovine serum. The 
$\mathbf{A}$

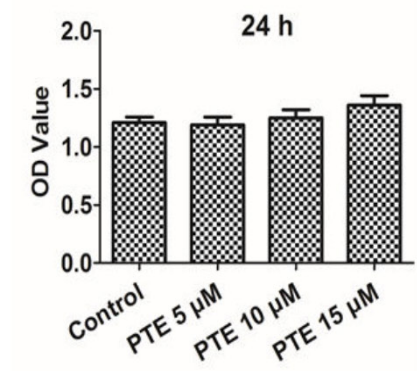

B
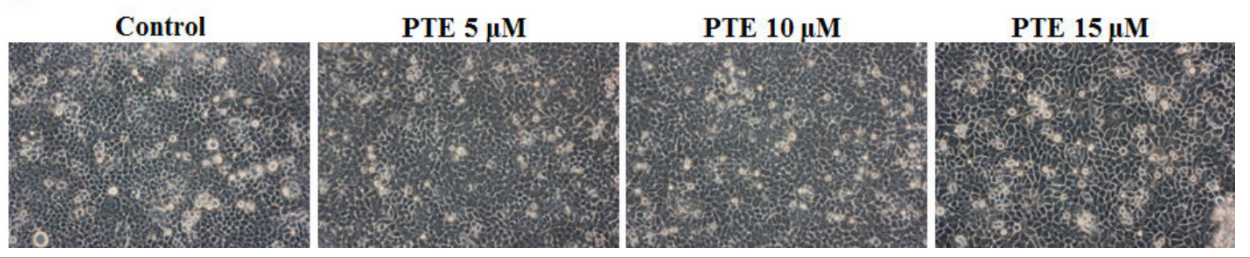

Fig. 1. Effects of low concentrations of PTE on the viability of human EC109 esophageal cancer cells. (A) EC109 cells were treated with PTE at low concentrations $(5,10$, and $15 \mu \mathrm{M})$ for $24 \mathrm{~h}$. Viability is expressed as OD values. (B) EC109 cell morphology was observed under an inverted phase-contrast microscope at the same time point, and images were obtained. The results are expressed as the means $\pm S D, n=6$. ${ }^{*} P<0.01$, compared with the control group, ${ }^{\# \#} \mathrm{P}<0.01$, compared with the $5 \mu \mathrm{M}$ PTE-treated group, ${ }^{\$ \$ \$} \mathrm{P}<0.01$, compared with the $10 \mu \mathrm{M}$ PTE-treated group. OD, optical density.

treated cells $\left(1 \times 10^{4}\right.$ cells per well $)$ were placed in a 96-well plate and allowed to adhere for $30 \mathrm{~min}$ at $37^{\circ} \mathrm{C}$. The cells were gently washed 3 times with PBS, and the adherent cells were stained with MTT and observed under an inverted phase-contrast microscope. Images were taken using a BX61 camera (Olympus Company, Osaka, Japan). Finally, $100 \mu \mathrm{l}$ of DMSO was added to each well, and the samples were incubated for $15 \mathrm{~min}$ at $37^{\circ} \mathrm{C}$ with shaking. The absorbance at $490 \mathrm{~nm}$ was measured using a SpectraMax 190 spectrophotometer (Molecular Devices, Sunnyvale, CA, USA), and the OD value of the control group was set as $100 \%$.

A cell culture wound-healing assay was performed to analyze cell migration. Cells were grown to confluence, and a linear wound was created in the confluent monolayer using a $200-\mu l$ micropipette tip. The cells were then washed with PBS to eliminate detached cells. After treatment with PTE $(5,10$ or $15 \mu \mathrm{M})$ for $24 \mathrm{~h}$, the movement of the wound edge was monitored under a microscope. The results are expressed as the distance between the cells on either side of the scratch.

Cell invasion assays were performed with using Corning Transwell Boyden chambers. Briefly, a total of $5 \times 10^{4}$ cells per well was seeded into the upper chamber with an insert pre-coated with $50 \mu \mathrm{l}$ matrigel and supplemented with PTE $(50,100$ or $150 \mu \mathrm{M})$. The chambers were then inserted into a 24-well culture plate, and the wells were filled with DMEM containing $10 \%$ fetal bovine serum. After culturing at $37^{\circ} \mathrm{C}$ for $24 \mathrm{~h}$, the cells remaining on the upper surface of the membranes were scraped off, and the cells on the lower surface were fixed, stained with $0.1 \%$ crystal violet, imaged, and counted under an inverted/phase-contrast microscope. Images were taken using a BX61 camera (Olympus Company, Osaka, Japan).

\section{Analyses of intracellular ROS generation and GSH levels}

The measurement of intracellular ROS was based on the ROS-mediated conversion of non-fluorescent 2', 7'-DCFH-DA into fluorescent DCFH. After treatment, cells were trypsinized and subsequently incubated with DCFH-DA $(20 \mu \mathrm{M})$ in PBS at $37^{\circ} \mathrm{C}$ for $2 \mathrm{~h}$. After incubation, the DCFH fluorescence of the cells in each well was measured using an FLX 800 microplate fluorescence reader, with $530 \mathrm{~nm}$ as the emission wavelength and $485 \mathrm{~nm}$ as the excitation wavelength (Biotech Instruments Inc., USA). A cell-free condition was used to determine the background, and the fluorescence intensity in the control group was defined as $100 \%$. The generation of intracellular reduced GSH, which is an index of the cellular reducing power, was measured using the appropriate kits according to the manufacturer's recommended instructions. The GSH level in the control group was set as $100 \%$. 


\section{Cellular Physiology Cell Physiol Biochem 2016;38:1226-1244 \begin{tabular}{l|l|l}
\hline DOI: 10.1159/000443071 & C 2016 S. Karger AG, Basel
\end{tabular} \begin{tabular}{l|l|l|l|l|l|l} 
and Biochemistry Published online: March 17, 2016 & www.karger.com/cpb \\
\cline { 1 - 2 }
\end{tabular}}

Feng et al.: PTE Inhibits Esophageal Cancer via ERS

\section{Analysis of Caspase 3 activity}

Caspase 3 activity was measured using a colorimetric assay kit according to the manufacturer's recommended instructions. Cells were washed in ice-cold PBS; proteins were then extracted and stored at $-80^{\circ} \mathrm{C}$. The cell lysates $(20 \mu \mathrm{l})$ were added to a buffer containing a p-nitroaniline (pNA)-conjugated substrate for Caspase 3 (Ac-DEVD-pNA) to yield a $100-\mu \mathrm{l}$ reaction volume. The reactions were performed at $37^{\circ} \mathrm{C}$. The released pNA concentrations were calculated based on the absorbance values at $405 \mathrm{~nm}$ and the calibration curve of the defined pNA solutions. The Caspase 3 activity in the control group was set as 100\%.

Isolation of mitochondrial and cytosolic fractions

Mitochondria were isolated according to a previous procedure, with slight modification [22]. Esophageal cancer cells were homogenized in ice-cold isolation buffer (0.25 mM sucrose, $1 \mathrm{mM}$ K-EDTA, $10 \mathrm{mM}$ Tris-HCl, pH 7.4) using a Teflon pestle. The homogenate was immediately centrifuged for $5 \mathrm{~min}$ at $2000 \times \mathrm{g}, 4^{\circ} \mathrm{C}$; the supernatant was centrifuged again for $3 \mathrm{~min}$ at $2000 \times \mathrm{g}$, and the second supernatant was decanted and centrifuged for $10 \mathrm{~min}$ at $12,000 \times \mathrm{g}$. The supernatant was discarded, and the pellet was re-suspended in isolation buffer without K-EDTA. The suspension was centrifuged for $10 \mathrm{~min}$ at $12,000 \times \mathrm{g}$. The resulting brown mitochondrial pellet was re-suspended in the same buffer, and the supernatant was considered the cytosolic fraction. The cytosolic and mitochondrial fractions were stored at $-80^{\circ} \mathrm{C}$ until use.

\section{Intracellular calcium measurement}

Intracellular free calcium in EC109 cells was determined using flow cytometric analysis according to the manufacturer's protocol [23]. Briefly, EC109 cells were grown for 24 hours in medium with different concentrations of PTE. The cells were collected, washed in PBS, and incubated for 30 min with $1 \mu \mathrm{M}$ calcium green-1-AM. Flow cytometric analysis of the stained cells was performed using a flow cytometer (BD FACSCanto $^{\mathrm{TM}}$ II; BD Biosciences).

\section{Small interfering RNA transfection}

For siRNA transfections, EC109 cells were plated into 6, 24 or 96-well plates and allowed to grow to subconfluency. The cells were transiently transfected for $24 \mathrm{~h}$ with negative control or CHOP siRNA at $50 \mathrm{pM}$ using the Lipofectamine RNAiMAX reagent (Invitrogen, Carlsbad, CA, USA) in OPTI-MEM medium (Gibco, Carlsbad, CA, USA). The cells were subsequently prepared for use in further experiments.

\section{Anticancer activity in a xenograft model}

Male, athymic nude mice were purchased from the Laboratory Animal Centre of the Fourth Military Medical University. The mice were housed and maintained under specific pathogen-free conditions in facilities approved by the American Association for Accreditation of Laboratory Animal Care and in accordance with current regulations and standards of the United States Department of Agriculture, United States Department of Health and Human Services. The present study was performed according to the Guide for the Care and Use of Laboratory Animals published by the US National Institutes of Health (National Institutes of Health Publication No. 85-23, revised 1996) and approved by the Ethics Committee of the Fourth Military Medical University. All surgery was performed under sodium pentobarbital anesthesia, and all efforts were made to minimize suffering. EC109 cell tumor xenografts were established by subcutaneously injecting $1 \times 10^{6}$ cells into the right flanks of 4- to 6-week-old male, athymic nude mice. Based on data from a pilot study, we initiated treatment when the tumor volume reached approximately $100 \mathrm{~mm}^{3}$; the tumor volumes (V) were calculated using the following formula: $\mathrm{V}=\mathrm{A} \times \mathrm{B}^{2} / 2(\mathrm{~A}=$ largest diameter; $\mathrm{B}=$ smallest diameter $)$. The mice were randomly divided into 3 groups ( $\mathrm{n}=6$ per group): control (0.05\% DMSO) and PTE at either 100 or 200 $\mathrm{mg} / \mathrm{kg}$ body weight. PTE was diluted with saline+DMSO and administered intraperitoneally (5 days/week). The tumor sizes were measured every 3 days using calipers (days 2, 5, 8, 11, 14, 17 and 20), and on day 20, the tumors were excised from euthanized mice for Western blot analysis.

\section{Western blotting}

Cell or tumor samples were lysed in sample buffer (150 mM Tris pH 6.8, 8 M urea, 50 mM DTT, 2\% sodium dodecyl sulfate, $15 \%$ sucrose, $2 \mathrm{mM}$ EDTA, $0.01 \%$ bromophenol blue, $1 \%$ protease and phosphatase inhibitor cocktails), sonicated, boiled, separated using an 8-12\% Bis/Tris gel with 5× MES buffer (Invitrogen) and transferred to an Immobilon NC membrane (Millipore). The membranes were blocked with 5\% nonfat 


\begin{tabular}{|c|c|c|}
\hline Cellular Physiology & Cell Physiol Biochem 2016;38:1226-1244 & \\
\hline and Biochemistry & $\begin{array}{l}\text { DOI: 10.1159/000443071 } \\
\text { Published online: March 17, } 2016\end{array}$ & $\begin{array}{l}\text { O } 2016 \text { S. Karger AG, Basel } \\
\text { www.karger.com/cpb }\end{array}$ \\
\hline
\end{tabular}

milk in TBST (150 mM NaCl, $50 \mathrm{mM}$ Tris $\mathrm{pH}$ 7.5, 0.1\% Tween-20) and then probed with antibodies against GRP78, ATF6, CHOP, Sp-1, or cytochrome c (1:500) or against p-PERK, p-eIF2 $\alpha$, Bcl-2, PUMA, Caspase 9, Caspase 12 , or $\beta$-actin $(1: 1000)$ overnight at $4^{\circ} \mathrm{C}$. The membranes were placed in blocking buffer, washed with TBST, probed with secondary antibodies (1:5000) in blocking buffer at room temperature for $90 \mathrm{~min}$ and washed. Fluorescence was detected using a BioRad imaging system (BioRad, USA), and the signals were quantified using Image Lab Software (BioRad, USA).

\section{Statistical analyses}

All of the values are presented as the mean \pm standard deviation (SD). Group comparisons were performed using ANOVA (SPSS 13.0). All of the groups were analyzed simultaneously using an LSD $t$ test. A difference of $\mathrm{P}<0.05$ was considered to be statistically significant.

\section{Results}

Effects of PTE treatment on the viability and apoptosis of human esophageal cancer cells

To investigate whether PTE has an anti-tumor role in esophageal cancer, the CCK-8 assay was used to evaluate cytotoxic effects on EC109 and TE1 cells; the data are presented in Fig. 2A and Fig. 3A. Treatment of EC109 and TE1 cells for 12, 24 or 36 h with 50, 100 and 150 $\mu \mathrm{M}$ PTE inhibited cell viability in a dose- and time-dependent manner. Microscopy images (Fig. 2B and Fig. 3B) indicated that PTE treatment resulted in significant cell shrinkage and decreased the rate of cellular attachment compared with the control group.

The apoptotic index of PTE-treated esophageal cancer cells was also measured. After treatment with 50,100 and $150 \mu \mathrm{M}$ PTE for $24 \mathrm{~h}$, the apoptotic index (Fig. 2C) increased to

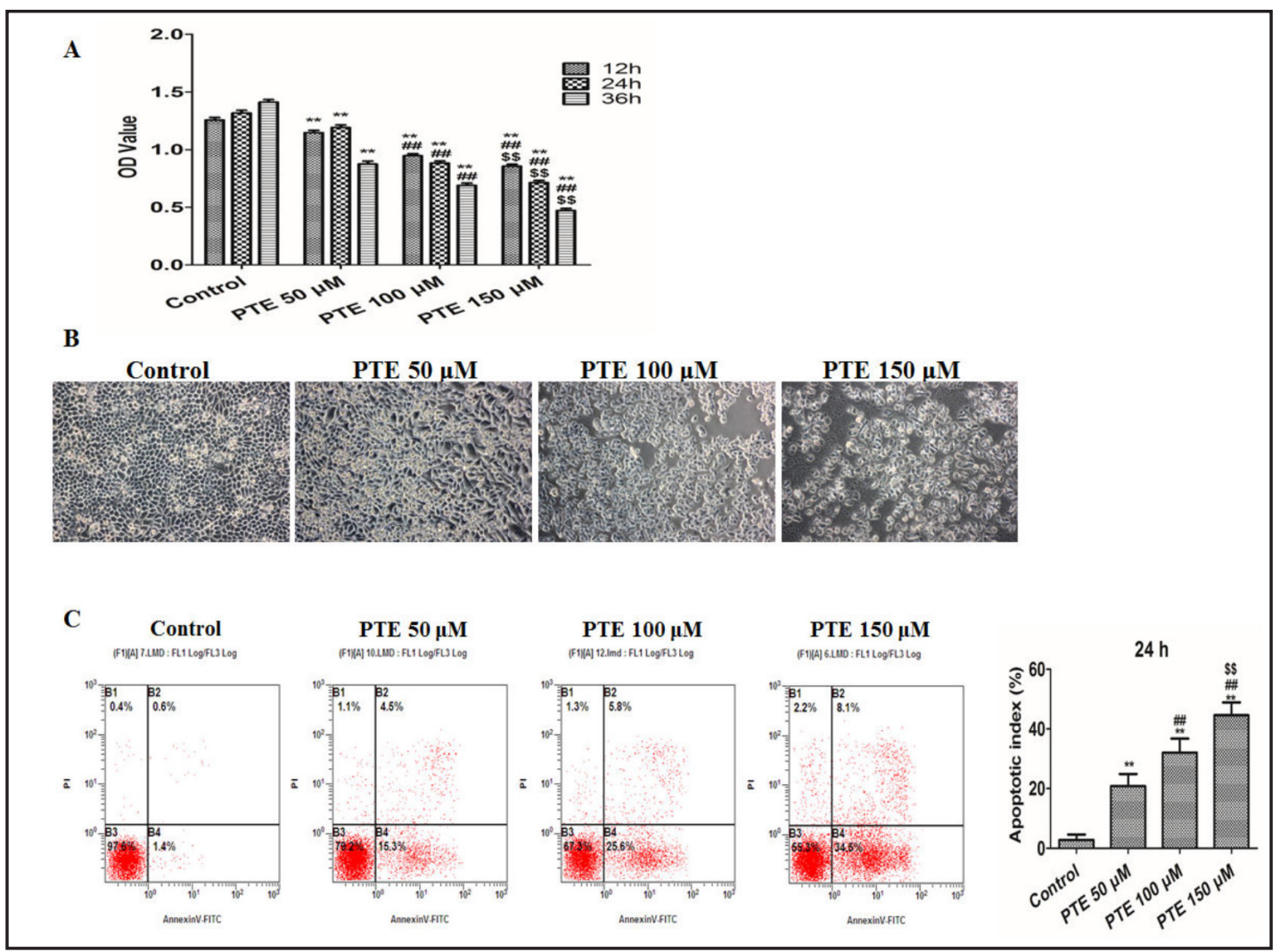

Fig. 2. Effects of PTE treatment on the viability and apoptosis of human EC109 esophageal cancer cells. (A) EC109 cells were treated with PTE at different concentrations (50,100 and $150 \mu \mathrm{M})$ and then assessed at different time points (12, 24 and $36 \mathrm{~h}$ ). Viability is expressed as OD values. (B) EC109 cell morphology was observed under an inverted phase-contrast microscope (after the cells had been treated for $24 \mathrm{~h}$ ), and 
images were obtained. Significant cell shrinkage and a decreased cellular attachment rate were observed in the PTE-treated group. The results are expressed as the means $\pm \mathrm{SD}, \mathrm{n}=6$. ${ }^{* *} \mathrm{P}<0.01$, compared with the control group, ${ }^{\# \# P}<0.01$, compared with the $50 \mu \mathrm{M}$ PTE-treated group, ${ }^{\$ \$} \mathrm{P}<0.01$, compared with the 100 $\mu$ M PTE-treated group. OD, optical density.

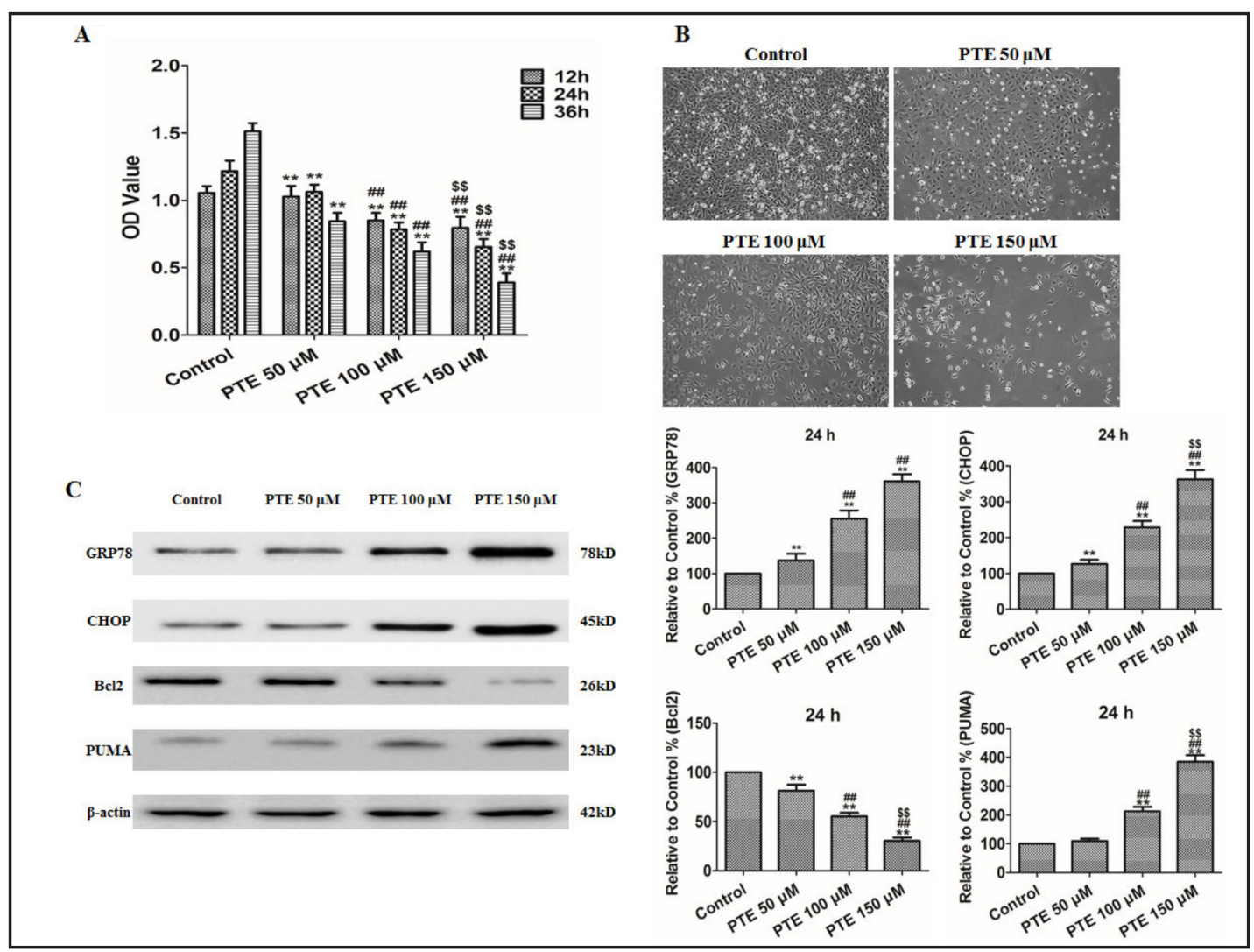

Fig. 3. Effects of PTE treatment on viability, ERS signaling, and apoptosis-associated proteins in human TE1 esophageal cancer cells. (A) TE1 cells were treated with PTE at different concentrations (50, 100, and 150 $\mu \mathrm{M}$ ) and then assessed at different time points (12, 24 and $36 \mathrm{~h}$ ). Viability is expressed as OD values. (B) TE1 cell morphology was observed under an inverted phase-contrast microscope (after the cells had been treated for $24 \mathrm{~h}$ ), and images were obtained. Significant cell shrinkage and a decreased cellular attachment rate were observed in the PTE-treated group. (C) Representative Western blot results for GRP78, CHOP, Bcl2 , and PUMA after PTE treatment for $24 \mathrm{~h}$ are shown. The results are expressed as the means $\pm \mathrm{SD}, \mathrm{n}=6$. ${ }^{* *} \mathrm{P}<0.01$, compared with the control group, ${ }^{\# \#} \mathrm{P}<0.01$, compared with the $50 \mu \mathrm{M}$ PTE-treated group, $\$ \$ \mathrm{P}<0.01$, compared with the $100 \mu \mathrm{M}$ PTE-treated group. OD, optical density.

$20.81 \pm 4.07 \%, 32.04 \pm 4.69 \%$ and $44.59 \pm 4.27 \%$, respectively $(\mathrm{P}<0.01$, compared with the control group), demonstrating that apoptosis induction was dose dependent. These results indicate that PTE induced apoptosis in EC109 cells.

Effects of PTE treatment on the migration, adhesion, and invasion of human esophageal cancer cells

Cell migration and adhesion were further evaluated in PTE-treated EC109 cells. After incubation with PTE $(5,10$ or $15 \mu \mathrm{M})$ for $24 \mathrm{~h}$, the cell adhesion ratio decreased significantly to $82.24 \pm 5.79 \%, 62.18 \pm 4.38 \%$ and $38.20 \pm 4.33 \%$, respectively $(\mathrm{P}<0.01$, compared with the control group, Fig. 4A), the distance between scratches increased significantly to 122.73 $\pm 7.30 \%, 136.61 \pm 7.12 \%$ and $169.45 \pm 10.04 \%$, respectively $(\mathrm{P}<0.01$, compared with the control group, Fig. 4B), and the invasion capability was markedly suppressed to $73.61 \pm$ $8.14 \%, 58.19 \pm 7.26 \%$ and $39.17 \pm 6.39 \%$, respectively $(\mathrm{P}<0.01$, compared with the control 


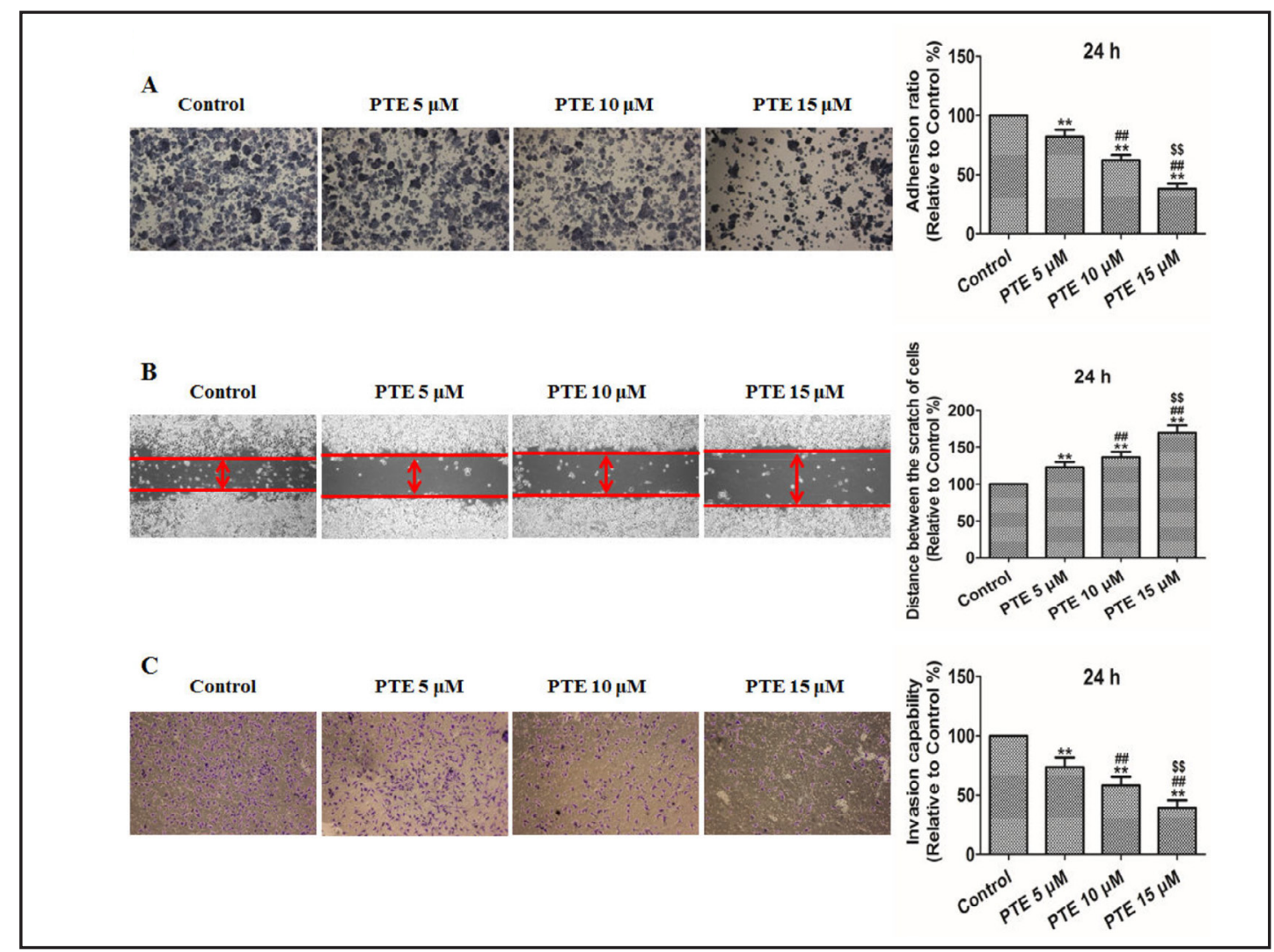

Fig. 4. Effects of PTE treatment on the migration, adhesion, and invasion of human EC109 esophageal cancer cells (24 h). (A) Representative adhesion images are shown. The cell adhesion ability is expressed as an adhesion ratio, and the number of adherent cells in the control group was set as $100 \%$.(B) Representative wound healing images are shown. The migratory ability is expressed as the mean distance between the two sides of the scratch. The mean distance in the control group was set as $100 \%$. (C) Representative invasive capability images are shown. The invasive capability is expressed as an invasion rates. The number of invasive cells in the control group was set as $100 \%$. The results are expressed as the means \pm SD, $n=6$.

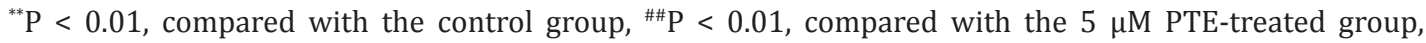
${ }_{\$} \mathrm{P}<0.01$, compared with the $10 \mu \mathrm{M}$ PTE-treated group.

group, Fig. 4C). These results indicate that PTE reduced the metastasis abilities of EC109 cells.

Effects of PTE treatment on ROS generation, Caspase 3 activity, GSH levels, and intracellular calcium levels in human esophageal cancer cells

To determine whether PTE causes intracellular oxidation, we used the specific oxidationsensitive fluorescent dye DCFH-DA, which exhibits enhanced fluorescence intensity following the generation of reactive metabolites. Treatment with PTE $(50,100$ or $150 \mu \mathrm{M})$ for 24 $\mathrm{h}$ resulted in a dose-dependent increase in ROS generation in EC109 cells (Fig. 5A), with increases of $205.45 \pm 12.18 \%, 317.80 \pm 16.39 \%$ and $547.71 \pm 25.63 \%$, respectively $(\mathrm{P}<0.01$, compared with the control group). Caspase 3 activity (Fig. 5B) also increased significantly to $364.95 \pm 15.23 \%, 434.61 \pm 22.84 \%$ and $467.29 \pm 25.37 \%$, respectively, after treatment with 50,100 and $150 \mu \mathrm{M}$ PTE $(\mathrm{P}<0.01$, compared with the control group). Reduced GSH is the major non-protein thiol in cells and is essential for maintaining the cellular redox status, and we observed a dose-dependent decrease $(76.49 \pm 4.25 \%, 64.32 \pm 4.08 \%$ and $39.14 \pm 3.61 \%$, respectively) in intracellular GSH levels after treatment with 50, 100 or $150 \mu \mathrm{M}$ PTE for $24 \mathrm{~h}$, $(\mathrm{P}<0.01$, compared with the control group, Fig. 5C). Moreover, the intracellular free calcium

\section{KARGER}


A

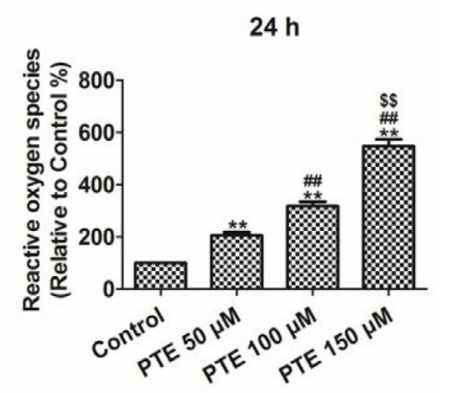

C

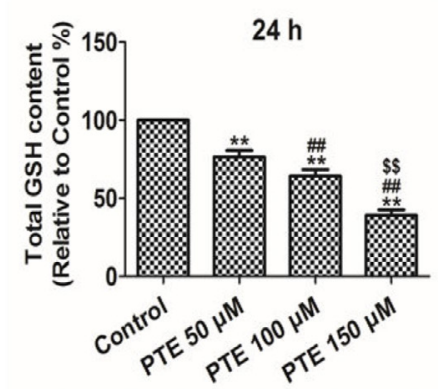

B

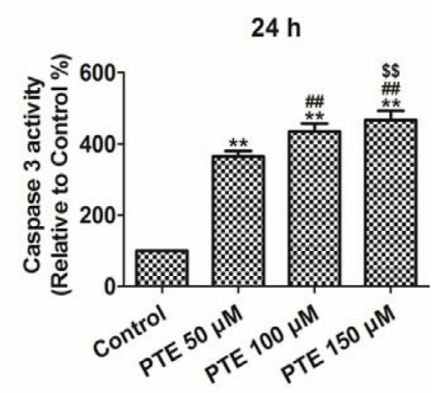

D

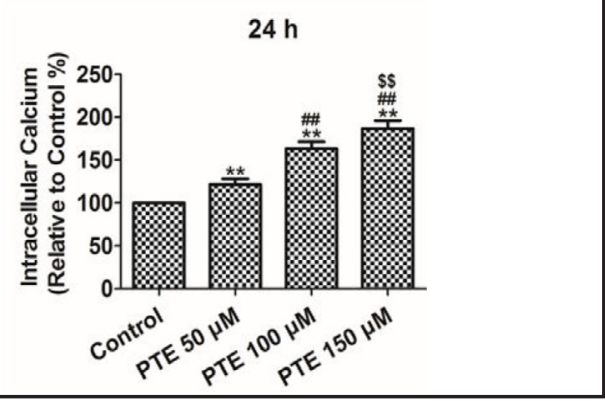

Fig. 5. Effects of PTE treatment on ROS generation, Caspase 3 activity, GSH levels, and intracellular calcium levels in human EC109 esophageal cancer cells (24 h). (A) ROS concentrations are shown. The fluorescence intensity in the control group was defined as 100\%. (B) Intracellular Caspase 3 activity levels are shown. The Caspase 3 activity level in the control group was defined as 100\%. (C) Intracellular GSH levels are shown. The GSH levels in the control group were defined as $100 \%$. (D) Intracellular calcium levels are shown. The calcium levels in the control group were defined as $100 \%$. The results are expressed as the means \pm SD, $\mathrm{n}=6$. " $\mathrm{P}<0.01$, compared with the control group, ${ }^{* \#} \mathrm{P}<0.01$, compared with the $50 \mu \mathrm{M}$ PTE-treated group, ${ }^{\$ \$} \mathrm{P}<0.01$, compared with the $100 \mu \mathrm{M}$ PTE-treated group, ${ }^{\$} \mathrm{P}<0.05$, compared with the $100 \mu \mathrm{M}$ PTE-treated group. ROS, reactive oxygen species. GSH, glutathione.

level was analyzed by calcium green-1-AM staining, showing a dose-dependent increase $(121.64 \pm 6.67 \%, 163.51 \pm 7.84 \%$ and $186.75 \pm 9.24 \%$, respectively) after treatment with different concentrations of PTE $(50,100$ or $150 \mu \mathrm{M})(\mathrm{P}<0.01$, compared with the control group, Fig. 5D). These results support the notion that PTE treatment affected the cellular redox status and calcium distribution.

Effects of PTE on ERS signaling, apoptosis-associated proteins, and Sp-1 in human esophageal cancer cells

To explore the role of ERS signaling in the anticancer activity of PTE, ERS-related molecules were detected by Western blot analysis. As shown in Fig. 6, PTE treatment induced a dose-dependent upregulation of GRP78, ATF6, p-PERK, p-eIF2 $\alpha$ and CHOP protein levels in EC109 cells ( $\mathrm{P}<0.01$, compared with the control group). Furthermore, we found that PTE treatment decreased the expression of Bcl-2 and increased the expression of PUMA while promoting the translocation of cytochrome c from mitochondria to cytosol and the activation of Caspase 9 and Caspase 12 ( $\mathrm{P}<0.01$, compared with the control group). Similar trends of GRP78, CHOP, Bcl-2, and PUMA expression were found in TE1 cells after PTE treatment, as shown in Fig. 3C. Sp-1 is a sequence-specific DNA-binding protein involved in the transcription of many important regulatory genes related to cancer development [24, 25]. After treating with different concentrations of PTE $(50,100$, and $150 \mu \mathrm{M})$ for $24 \mathrm{~h}, \mathrm{Sp}-1$ protein expression was decreased significantly $(\mathrm{P}<0.01$, compared with the control group), as shown in Fig. 6. 


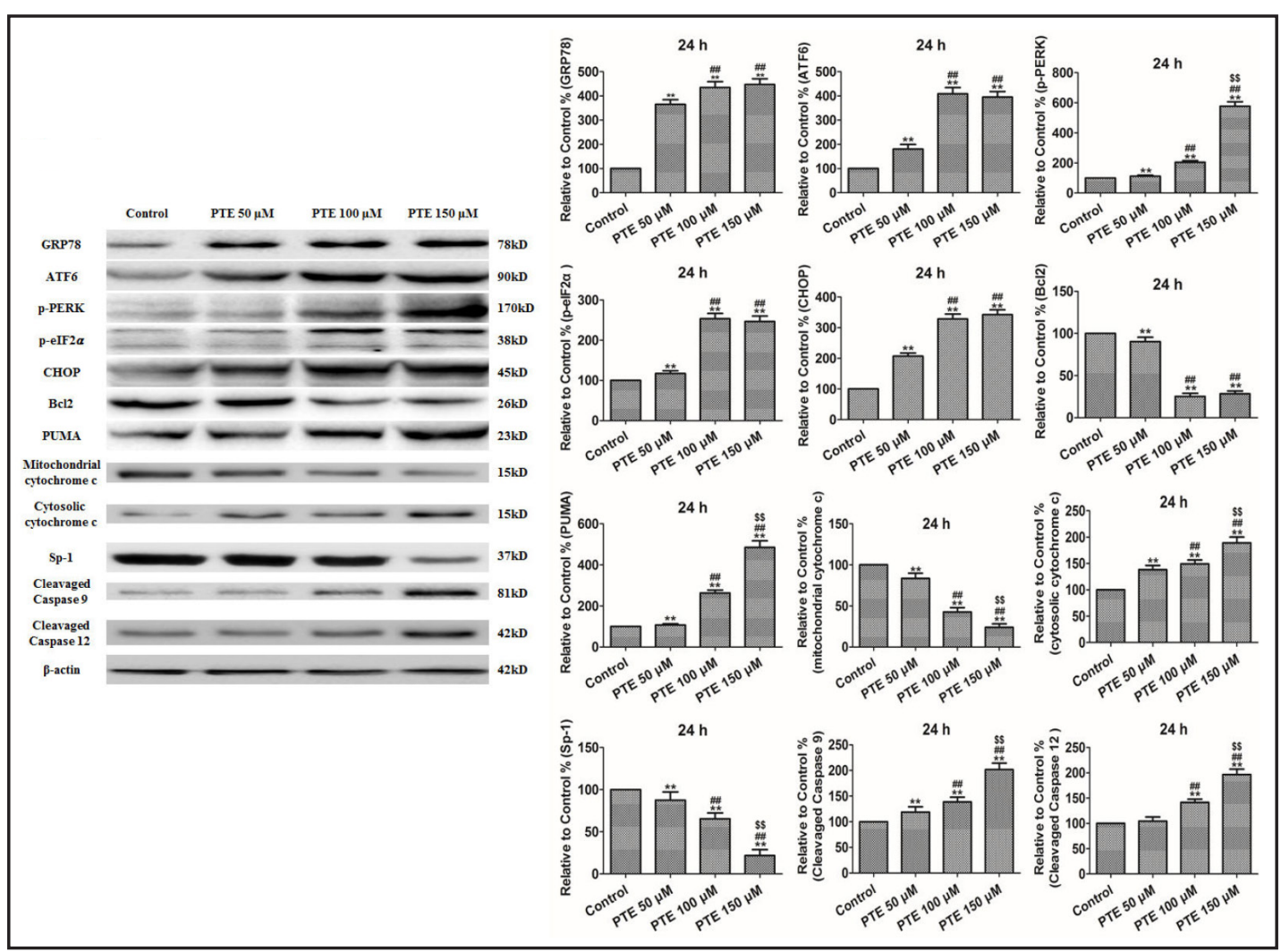

Fig. 6. Effects of PTE on ERS signaling, apoptosis-associated proteins, and Sp-1 in human EC109 esophageal cancer cells (24 h). Representative Western blotting results for GRP78, ATF6, p-PERK, p-eIF2 $\alpha$, CHOP, Bcl-2, PUMA, mitochondrial cytochrome c, cytosolic cytochrome c, Sp-1, and activation of Caspase 9 and Caspase 12 are shown. ${ }^{* *} \mathrm{P}<0.01$, compared with the control group, ${ }^{\# \#} \mathrm{P}<0.01$, compared with the $50 \mu \mathrm{M}$ PTE-treated group, ${ }^{\$} \mathrm{P}<0.01$, compared with the $100 \mu \mathrm{M}$ PTE-treated group.

Effects of PTE combined with CHOP siRNA on cell viability, ROS induction, Caspase 3 activity and CHOP expression in human esophageal cancer cells

A significant decrease in CHOP expression was observed when EC109 cells were first incubated with CHOP siRNA for $24 \mathrm{~h}$ and then subjected to PTE $(100 \mu \mathrm{M})$ treatment for another $24 \mathrm{~h}(\mathrm{P}<0.01$, compared with the control siRNA group, Fig. 7D). The combination of CHOP siRNA+PTE significantly increased cell viability (Fig. 7A), reduced ROS (Fig. 7B) and decreased Caspase 3 activity (Fig. 7C) ( $\mathrm{P}<0.01$, compared with the control siRNA+PTE group), whereas CHOP siRNA alone had no effect on cell viability, ROS induction or Caspase 3 activity compared with the control siRNA group (P > 0.05). Additionally, PUMA was downregulated and Bcl-2 upregulated in the CHOP siRNA+PTE group ( $<0.01$, compared with the control siRNA+PTE group, Fig. 7D). The translocation of cytochrome $\mathrm{c}$ from mitochondria to cytosol was also reduced compared with the control siRNA+PTE group (P < 0.01, Fig. 7D).

Effects of PTE combined with THA on cell viability, ROS induction, Caspase 3 activity and CHOP expression in human esophageal cancer cells

THA, which causes calcium leakage from the ER into the cytosol, is a classical ERS inducer [26]. We further combined PTE $(100 \mu \mathrm{M})$ with THA and determined the cytotoxic efficiency in EC109 cells after $24 \mathrm{~h}$. Based on our preliminary study, a relatively low concentration of THA $(1 \mu \mathrm{M})$ was chosen, such that potential enhancing effects would be more prominent. The OD value in the control group was $1.305 \pm 0.034$; PTE treatment alone decreased the OD value to $0.816 \pm 0.029$, and THA treatment alone slightly decreased the OD value to 1.029 \pm 0.035 (Fig. 8A). However, when PTE was combined with THA, the OD value decreased significantly to $0.507 \pm 0.026$. The combination index (CI) was calculated according to a 


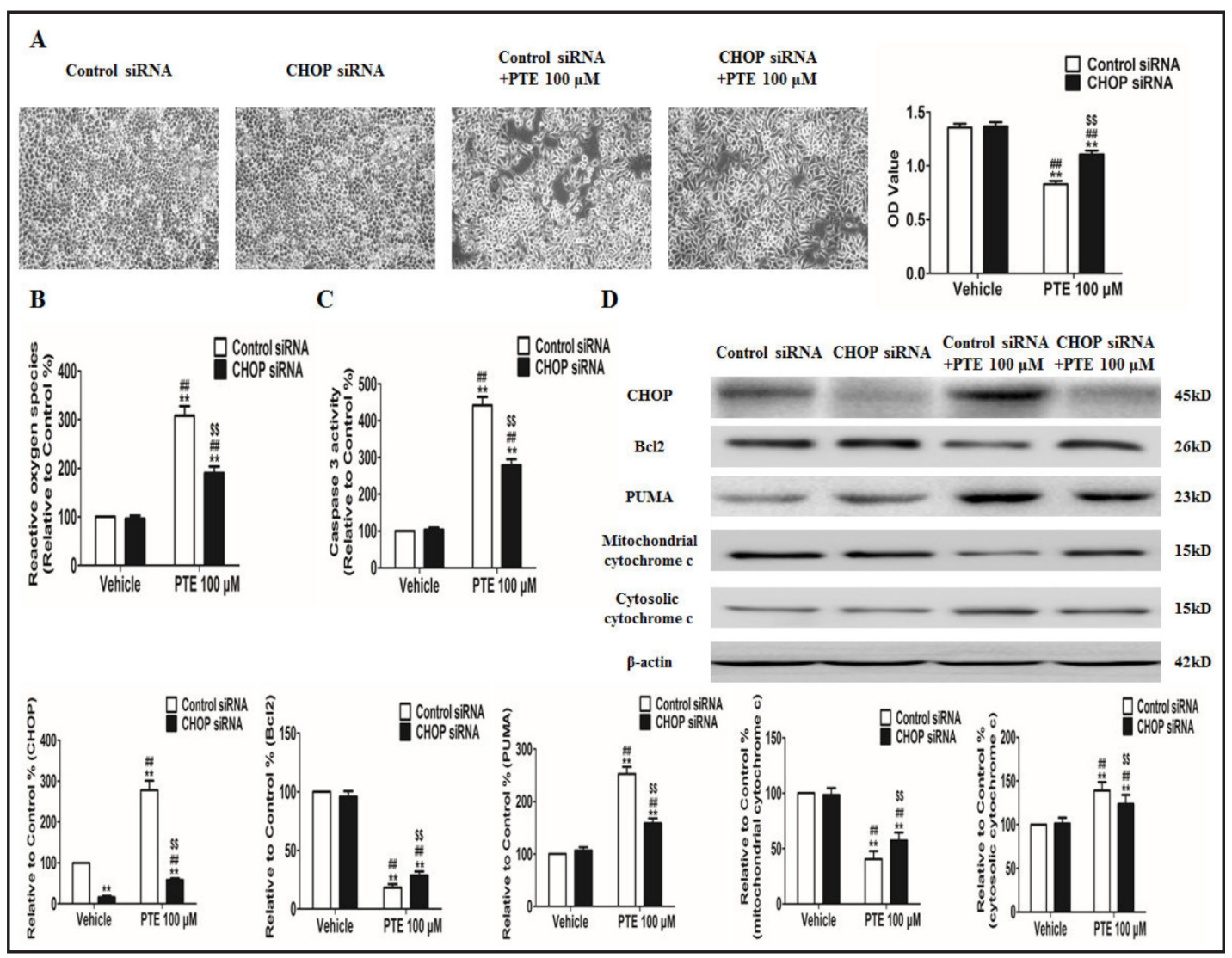

Fig. 7. Effects of PTE combined with CHOP siRNA on cell viability, ROS induction, Caspase 3 activity and CHOP expression in human EC109 esophageal cancer cells. (A) Viability is expressed as OD values. Cell morphology was observed under an inverted phase-contrast microscope, and images were obtained. (B) ROS concentrations are shown. The fluorescence intensity in the control group was defined as $100 \%$. (C) Intracellular Caspase 3 activity levels are shown. The Caspase 3 activity level in the control group was defined as $100 \%$. (D) Representative Western blot results for CHOP, Bcl-2, PUMA, mitochondrial cytochrome c, and cytosolic cytochrome $\mathrm{c}$ are shown. The results are expressed as the means $\pm \mathrm{SD}, \mathrm{n}=6 .{ }^{* *} \mathrm{P}<0.01$, compared with the control siRNA-treated group, ${ }^{\# \# P}<0.01$, compared with the CHOP siRNA-treated group, ${ }^{\$} \mathrm{P}<0.01$, compared with the control siRNA + PTE $100 \mu \mathrm{M}$ PTE-treated group.

previous study [27], where $\mathrm{CI}<1$ is synergistic, $\mathrm{CI}=1$ is additive, and $\mathrm{CI}>1$ is antagonistic. The CI for this treatment was approximately 0.604 , which indicated that the combined effect of PTE and THA was synergistic. The combination of PTE+THA also significantly induced ROS (Fig. 8B) and increased Caspase 3 activity (Fig. 8C) ( $\mathrm{P}<0.01$, compared with the PTE or THA groups). As shown in Fig. 8D, THA significantly increased CHOP expression in EC109 cells $(\mathrm{P}<0.01$, compared with the control group, Fig. 8D), and co-treatment of EC109 cells with PTE+THA further increased CHOP expression compared with either treatment alone $(\mathrm{P}<0.01)$. Additionally, PUMA was further upregulated and Bcl-2 further downregulated by PTE+THA co-treatment ( $\mathrm{P}<0.01$, compared with the PTE or THA groups). The translocation of cytochrome c from mitochondria to cytosol was also further enhanced compared with the PTE-treatment group ( $<<0.01$, Fig. 8D).

Effects of PTE combined with NAC on cell viability, ROS induction, Caspase 3 activity, and Sp-1 expression in human esophageal cancer cells

NAC is a well-established thiol antioxidant that acts either by reducing cysteine groups in proteins and small peptides or serving as a GSH precursor that directly or enzymatically leads to ROS detoxification [28]. To examine whether PTE-induced cell death is mediated 


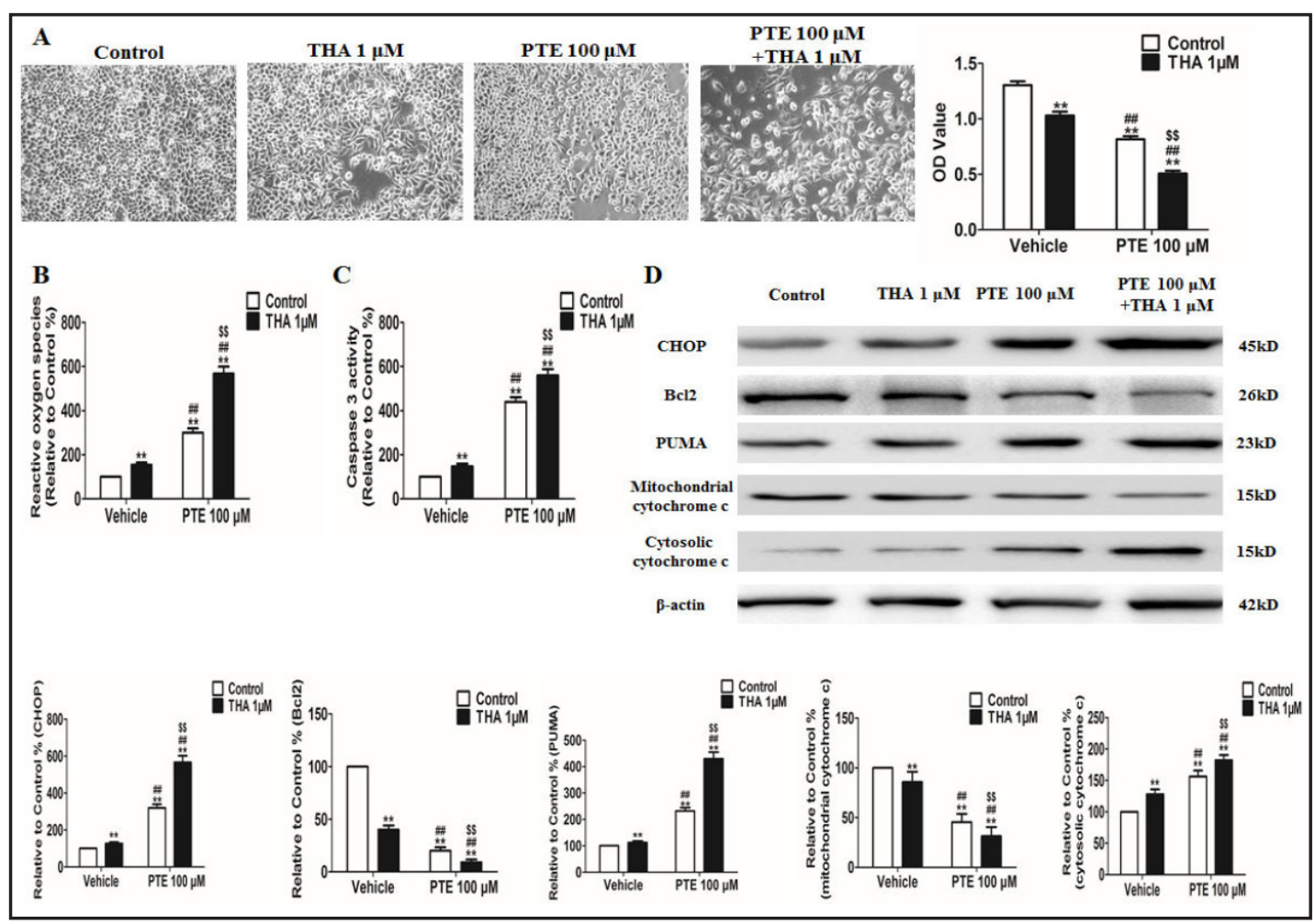

Fig. 8. Effects of PTE combined with THA on cell viability, ROS induction, Caspase 3 activity and CHOP expression in human EC109 esophageal cancer cells. (A) Viability is expressed as OD values. Cell morphology was observed under an inverted phase-contrast microscope, and images were obtained. (B) ROS concentrations are shown. The fluorescence intensity in the control group was defined as $100 \%$. (C) Intracellular Caspase 3 activity levels are shown. The Caspase 3 activity level in the control group was defined as $100 \%$. (D) Representative Western blot results for CHOP, Bcl-2, PUMA, mitochondrial cytochrome c, and cytosolic cytochrome $\mathrm{c}$ are shown. The results are expressed as the means $\pm \mathrm{SD}, \mathrm{n}=6{ }^{* *} \mathrm{P}<0.01$, compared with the control group, ${ }^{\# \#} \mathrm{P}<0.01$, compared with the THA-treated group, ${ }^{\$} \mathrm{P}<0.01$, compared with the $100 \mu \mathrm{M}$ PTE-treated group. THA, thapsigargin.

through ROS production, we treated cells with NAC $(10 \mathrm{mM} ; 20 \mathrm{mM}$ NAC stock solution prepared in DMEM) for $1 \mathrm{~h}$ followed by PTE $(100 \mu \mathrm{M})$ for an additional $24 \mathrm{~h}$ and then evaluated the cells for viability, ROS induction, and Caspase 3 activity; the concentration of NAC was selected according to a previous study [29]. As shown in Fig. 9A, the OD value in the control group was $1.11 \pm 0.073$, and PTE treatment alone decreased the OD value to $0.75 \pm 0.056$. However, when we pre-treated the cells with NAC, the OD value increased significantly to $0.823 \pm 0.065$ ( $\mathrm{P}<0.01$, compared with the PTE groups), and the increases in ROS (Fig. 9B), Caspase 3 activation (Fig. 9C), and Sp-1 downregulation were significantly reversed (Fig. 9D) ( $\mathrm{P}<0.01$, compared with the PTE groups).

\section{Effects of PTE on tumor xenograft growth and ERS signaling in vivo}

In vivo tumor xenograft experiments were carried out to verify our in vitro results. To determine whether PTE can inhibit tumor growth in animals, we established EC109 xenografts in athymic nude mice, with all treatment groups developing subcutaneous tumors. As shown in Fig. 10A, PTE treatment (100 or $200 \mathrm{mg} / \mathrm{kg}$ ) significantly inhibited tumor growth ( $\mathrm{P}<0.01$, compared with the control group). Additionally, Western blot analysis showed that PTE treatment induced a dose-dependent upregulation of GRP78, CHOP and PUMA and downregulation of Bcl-2 ( $\mathrm{P}<0.01$, compared with the control group, Fig. 10B).

\section{KARGER}




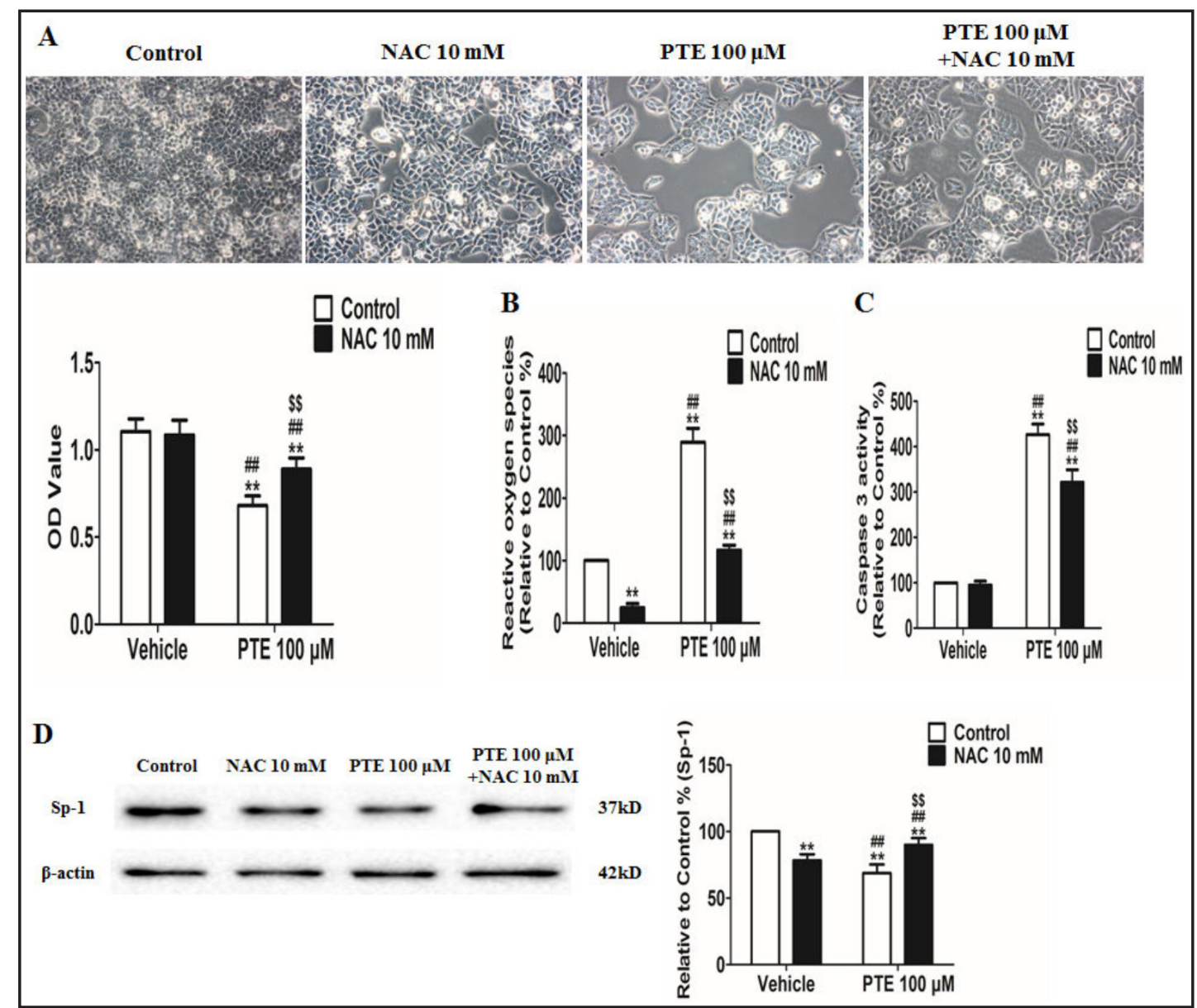

Fig. 9. Effects of PTE combined with NAC on viability, ROS induction, Caspase 3 activity, and Sp-1 expression in human EC109 esophageal cancer cells. (A) Viability is expressed as OD values. Cell morphology was observed under an inverted phase-contrast microscope, and images were obtained. (B) ROS concentrations are shown. The fluorescence intensity in the control group was defined as $100 \%$. (C) Intracellular Caspase 3 activity levels are shown. The Caspase 3 activity level in the control group was defined as $100 \%$. (D) $\mathrm{Sp}-1$ expression is shown. The Sp-1 expression in the control group was defined as $100 \%$. The results are expressed as the means $\pm \mathrm{SD}, \mathrm{n}=6 .{ }^{* *} \mathrm{P}<0.01$, compared with the control group, ${ }^{\# \# P}<0.01$, compared with the NAC-treated group, ${ }^{\$ \$} \mathrm{P}<0.01$, compared with the $100 \mu \mathrm{M}$ PTE-treated group. NAC, N-acetylcysteine.

\section{Discussion}

As a natural dimethylated analog of resveratrol, PTE has been shown to suppress the proliferation of different cancer cells. Various molecules and signaling pathways are involved in the anti-tumor effects of PTE. For instance, PTE induces the accumulation of autophagic vacuoles followed by cell death in HL60 human leukemia cells [6], and the activation of AMPK by PTE suppresses lipogenesis and cell-cycle progression in human prostate cancer cells [8]. However, the effects of PTE on human esophageal cancer have not yet been elucidated. In the present study, we found that PTE treatment dose- and time-dependently inhibited the viability of and induced apoptosis in EC109 esophageal cancer cells. PTE also significantly blocked EC109 cell adhesion and migration, which are major events determining tumor metastatic potential, and significantly inhibited tumor growth in EC109 xenografts.

Under ERS, the fate of cells depends on the balance between cell adaptive and cell death responses. ERS protects against tumor development by activating adaptive stress responses and attenuating apoptotic pathways, and forced activation of ERS can lead to the reactivation of ERS-dependent apoptotic pathways to retard tumor development, growth and invasion 


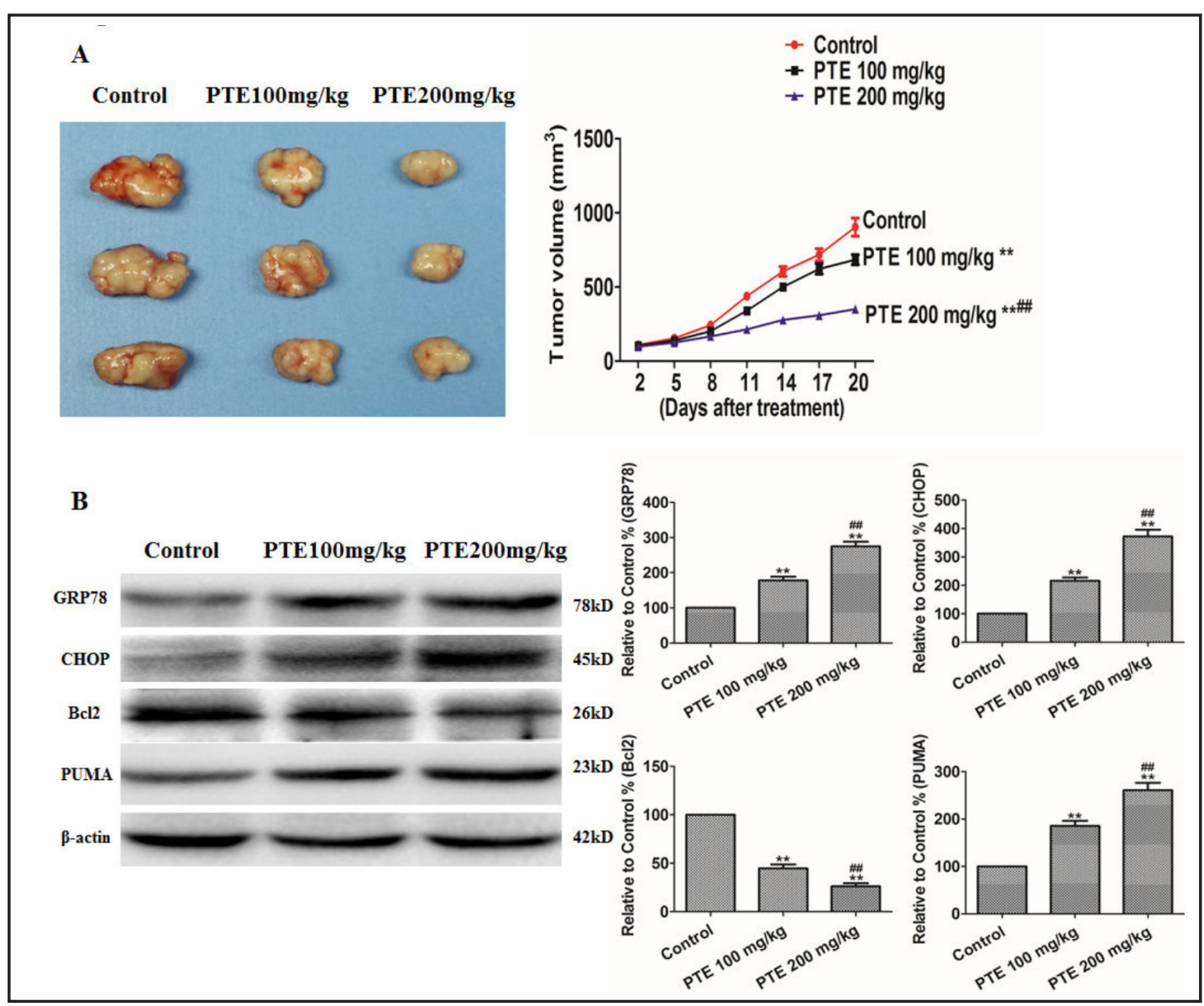

Fig. 10. Effects of PTE on EC109 tumor xenografts in vivo. (A) Photographs showing tumor xenograft morphologies in the various groups; a tumor growth curve was drawn from the tumor volumes and treatment duration. (B) Representative Western blot results for GRP78, CHOP, Bcl-2 and PUMA are shown. The results are expressed as the means $\pm \mathrm{SD}, \mathrm{n}=6 .{ }^{* *} \mathrm{P}<0.01$, compared with the control group; ${ }^{\# \#} \mathrm{P}<0.01$, compared with the PTE $100 \mathrm{mg} / \mathrm{kg}$ group.

[30]. It is worth noting that ERS is involved in the anticancer activity of resveratrol and that PTE is a dimethylated analog of resveratrol [5]. For example, Chow and colleagues showed that ER expansion and ER-Caspase 12 upregulation were important for the profound biological effects of resveratrol, which contributed to the death of human nasopharyngeal carcinoma cells [18]. Thus, targeting different ERS statuses may provide a strategy for cancer treatment [18]. Wang and colleagues found that resveratrol triggers the pro-apoptotic ERS response and represses pro-survival X-box binding protein 1 (XBP1) signaling in human multiple myeloma cells [21]. We further explored the role of ERS in the anticancer effect of PTE against human esophageal cancer cells, and our results indicate that PTE upregulated GRP78, ATF6, p-PERK, p-eIF2 $\alpha$ and CHOP expression in EC109 cells and increased the intracellular calcium level. PTE also significantly induced GRP78 and CHOP expression in EC109 xenografts, and knockdown of the ERS response protein CHOP by siRNA in vitro significantly reduced PTEinduced cell death. Moreover, the anticancer effect of PTE was synergistically enhanced in combination with THA, which further aggravated ERS. These data suggest that PTE exerts anticancer effects against esophageal cancer cells partially through the activation of ERS.

The Bcl-2 family plays a crucial role in the apoptotic process of various cancers [17]. PUMA and Bcl-2 are two important members of the Bcl-2 family: the latter is an antiapoptotic protein [2]; the former is normally expressed at a low level, but its expression is markedly induced after exposure to DNA-damaging agents, such as chemotherapeutic drugs 


\section{Cellular Physiology Cell Physiol Biochem 2016;38:1226-1244 \begin{tabular}{ll|l} 
and Biochemistry & $\begin{array}{l}\text { DOI: 10.1159/000443071 } \\
\text { Published online: March 17, 2016 }\end{array}$ & $\begin{array}{l}\text { O 2016 S. Karger AG, Basel } \\
\text { www.karger.com/cpb }\end{array}$ \\
\cline { 2 - 3 }
\end{tabular} \\ Feng et al.: PTE Inhibits Esophageal Cancer via ERS}

and ionizing radiation [31]. Previous studies have indicated that ERS activation influences these two molecules to ultimately regulate cell apoptosis [20]. Our results indicate that PTE downregulated Bcl-2 expression and upregulated PUMA expression in EC109 cells. Further analyses confirmed that inhibition of ERS with CHOP siRNA reversed the effects of PTE on Bcl-2 and PUMA expression, whereas activation of ERS by THA enhanced these PTE effects. These results indicate that PTE induces apoptosis by regulating the Bcl-2 family, confirming that the activation of ERS can affect these two Bcl-2 family molecules to regulate cell apoptosis [20].

Specificity protein $1(\mathrm{Sp}-1)$ is a sequence-specific DNA-binding protein involved in numerous pathological processes, such as inflammation, cancer-cell adhesion, tumor invasion, metastasis, and angiogenesis [24, 25, 32, 33]. Papineni et al. reported tolfenamic acid (TA)-dependent downregulation of Sp transcription factors and c-Met as a novel chemotherapeutic approach for treatment of esophageal cancer [34]. Moreover, some studies have demonstrated that Sp-1 inhibition is coupled with ROS induction. For example, in rhabdomyosarcoma, the inhibition of cell growth, survival and invasion and repression of Sp transcription factors by the HDAC inhibitors depend on ROS [35]. Similarly, celastrolinduced growth inhibition and repression of Sp1, Sp3 and Sp4 in bladder cancer cells can be blocked by ROS inhibitors [36]. Importantly, resveratrol inhibits u-PA expression and HCC cell metastasis through the downregulation of Sp-1 [37]. Accordingly, as a natural dimethylated analog of resveratrol, PTE may regulate $\mathrm{Sp}-1$ protein and ROS to exert anti-cancer effects against EC109 cells. Based on our results, NAC (a ROS scavenger) pre-treatment reversed the downregulation of $\mathrm{Sp}-1$ protein expression induced by PTE and attenuated the anticancer effects of PTE against esophageal cancer cells, indicating ROS-dependent suppression of Sp-1 as the possible mechanism by which PTE might prevent and treat esophageal cancer.

As multi-faceted signaling molecules involved in various cellular functions, ROS have key roles in the determination of cell fate: death or survival [5]. ROS have recently been identified as potential targets for novel anti-cancer drugs [38], and numerous investigations suggest that ERS could be either a cause or a result of increased ROS generation $[38,39]$. Thus, the roles of ROS generation and ERS in cell death have attracted much attention. In the present study, the pro-apoptotic effects of PTE in EC109 cells were found to be associated with rapid increases in intracellular ROS. Furthermore, inhibition of ERS by CHOP siRNA attenuated PTEinduced ROS production, whereas activation of ERS with THA enhanced PTE-induced ROS production. GSH is a major non-protein cellular antioxidant that can eliminate intracellular ROS [40]; the degree of ROS exposure and perturbations in the GSH redox balance are critical for determining whether cells undergo pro-survival or pro-death responses [5]. Our study also showed that PTE-induced ROS generation is associated with significant depletion in the intracellular GSH pool. The mitochondrial apoptotic pathway is generally thought to involve the translocation of cytochrome c from mitochondria to cytosol [41], and the release of cytochrome $\mathrm{c}$ activates Caspase 9 in the presence of deoxyadenosine triphosphate (dATP), resulting in apoptosis $[41,42]$. Furthermore, the ERS-mediated apoptotic pathway is initiated by the activation of Caspase 12, which can directly activate pro-Caspase 9 independently of mitochondrial cytochrome c [43]. In addition to Caspase 12 activation, ERS also triggers the activation of Caspase 8, which can promote the release of mitochondrial cytochrome $\mathrm{c}$ [44]. In particular, increased ROS originating from mitochondria plays important roles in mitochondrial-induced apoptosis, whereby potential collapse of the mitochondrial outer membrane contributes to the release of the pro-apoptotic factor cytochrome c from the inter-membrane space to the cytosol and activates caspases involved in the mitochondrial apoptotic pathway $[16,45,46]$. Conversely, inhibition of ROS desensitizes cancer cells to anti-cancer treatments $[28,29]$. In our study, PTE treatment of EC109 cells significantly increased cytochrome c translocation from mitochondria to cytosol and activated Caspase 9 and Caspase 12, further promoting ROS generation. This translocation of cytochrome c induced by PTE was attenuated by CHOP siRNA-mediated inhibition of ERS but enhanced by activation of ERS by THA. In addition, NAC (a ROS scavenger) blocked the induction of both ROS and Caspase 3 activity as well as the reduction in cell viability caused by PTE, 


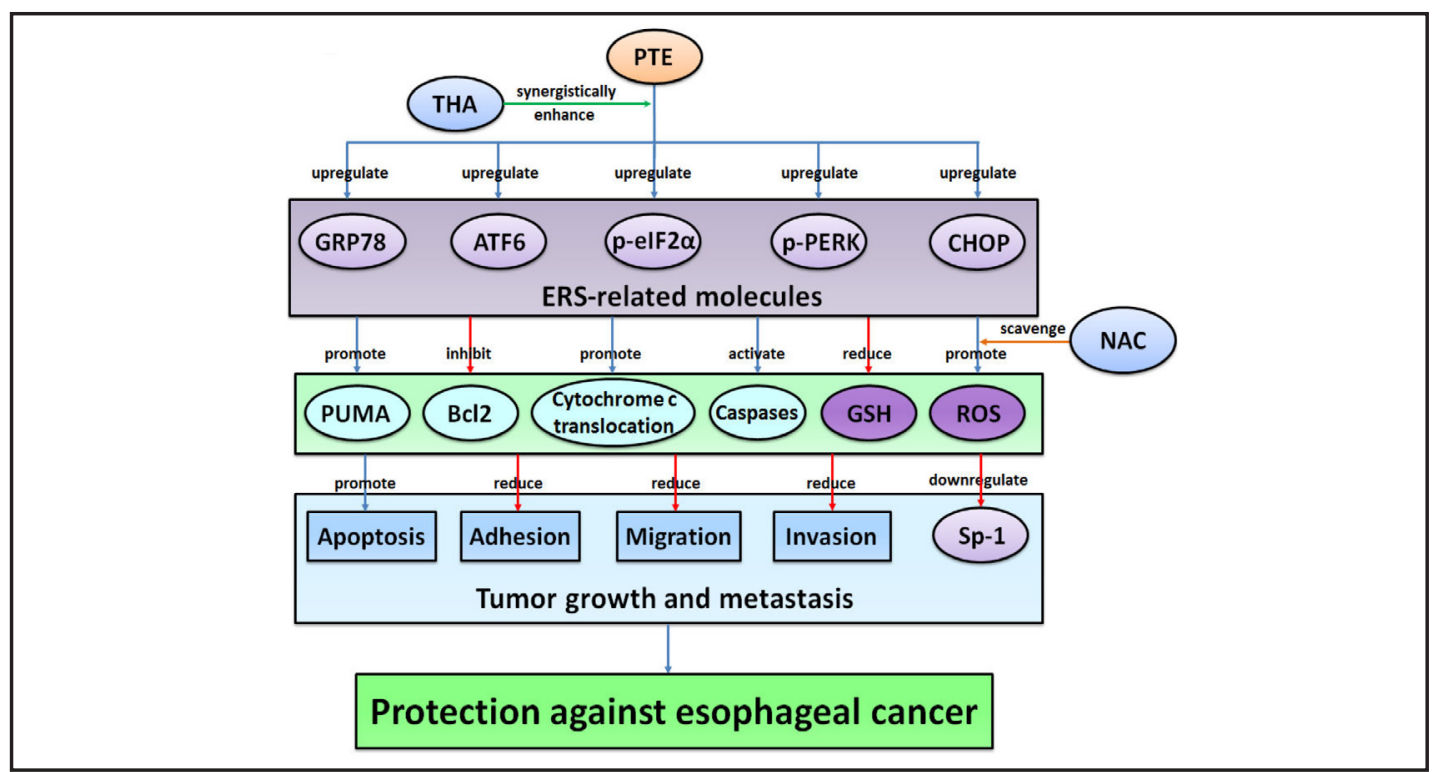

Fig. 11. The ERS-dependent mechanism of PTE-mediated protection against human esophageal cancer. PTE can upregulate a series of ER-related molecules (including GRP78, ATF6, p-PERK, p-eIF2 $\alpha$, and CHOP) and downregulate Sp-1. Activated ERS signaling can upregulate the apoptosis-related protein PUMA, downregulate the anti-apoptosis-related protein $\mathrm{Bcl}-2$, promote the translocation of cytochrome c from mitochondria to cytosol, and activate Caspase 9 and Caspase 12. Intracellular GSH levels are reduced, and ROS are increased. These events together might lead to apoptosis and reduce the adhesive, migratory, and invasion abilities of tumor cells, ultimately conferring protection against human esophageal cancer. In addition, THA can synergistically enhance the anticancer effect of PTE, whereas NAC can abolish the anticancer effect of PTE. PTE, pterostilbene; ERS, endoplasmic reticulum stress; GSH, glutathione; ROS, reactive oxygen species; THA, thapsigargin; ATF6, activating transcription factor 6; GRP78, glucose-regulated protein 78; CHOP, C/ EBP homologous protein; eIF2 $\alpha$, eukaryotic translational initiation factor 2; PUMA, p53 upregulated modulator of apoptosis; PERK, PKR-like ER kinase; Bcl2, B-cell lymphoma-2; Sp-1, specificity protein 1; NAC, $\mathrm{N}$-acetylcysteine.

which indicated that the anticancer effects of PTE against EC109 cells were dependent on ROS. Overall, these findings suggest that induction of the ERS-mediated ROS-mitochondriadependent pro-apoptotic mechanism contributes to the anticancer effects of PTE in human esophageal cancer cells.

These experiments provide in vivo and in vitro evidence that PTE exerts anticancer effects in human esophageal cancer cells by activating ERS. Downregulation of ERS signaling desensitizes esophageal cancer cells to PTE treatment, whereas its upregulation sensitizes these cells to PTE treatment. Additionally, ERS activation may contribute to the potentiation of chemosensitivity, which is associated with pro-apoptotic pathway upregulation (summarized in Fig. 11). Therefore, we propose that the activation of ERS signaling may be a novel strategy for preventing the induction of cancer pro-survival processes in advanced esophageal cancer.

\section{Abbreviations}

PTE (pterostilbene); ER (endoplasmic reticulum); ERS (endoplasmic reticulum stress); GSH (glutathione); ROS (reactive oxygen species); THA (thapsigargin); UPR (unfolded protein response); ATF6 (activating transcription factor 6); PERK (PKR-like ER kinase); IRE1 (inositol-requiring enzyme 1); GRP78 (glucose-regulated protein 78); 
CHOP (C/EBP homologous protein); eIF2 $\alpha$ (eukaryotic translational initiation factor 2); PUMA (p53 upregulated modulator of apoptosis); DMSO (dimethyl sulfoxide); MTT (3-(4,5-Dimethylthiazol-2-yl)-2,5-diphenyltetrazolium bromide); NAC (N-acetylcysteine); DCFH-DA (2',7'-dichlorofluorescein diacetate); p-PERK (phosphorylated-PERK); FITC/PI (fluorescein isothiocyanate-Annexin V/propidium iodide); CCK-8 (Cell Counting Kit-8); OD (optical density); SD (standard deviation); Sp-1 (specificity protein 1); XBP1 (X-box binding protein 1).

\section{Acknowledgments}

This work was supported by National Natural Science Foundation of China (81500263) and China Postdoctoral Science Foundation (2015M572681).

\section{Disclosure Statement}

The authors declare that there are no conflicts of interest.

\section{References}

1 Alexandre L, Clark AB, Bhutta HY, Holt S, Lewis MP, Hart AR: Statin use is associated with reduced risk of histologic subtypes of esophageal cancer: A nested case-control analysis. Gastroenterology 2014;146:661668.

2 Zhang S, Yang Y, Liang Z, Duan W, Yang J, Yan J, Wang N, Feng W, Ding M, Nie Y, Jin Z: Silybin-mediated inhibition of notch signaling exerts antitumor activity in human hepatocellular carcinoma cells. PLoS One 2013;8:e83699.

3 McCormack D, McFadden D: Pterostilbene and cancer: Current review. J Surg Res 2012;173:e53-61.

4 Ruiz MJ, Fernandez M, Pico Y, Manes J, Asensi M, Carda C, Asensio G, Estrela JM: Dietary administration of high doses of pterostilbene and quercetin to mice is not toxic. J Agric Food Chem 2009;57:3180-3186.

5 Yang Y, Duan W, Liang Z, Yi W, Yan J, Wang N, Li Y, Chen W, Yu S, Jin Z, Yi D: Curcumin attenuates endothelial cell oxidative stress injury through notch signaling inhibition. Cell Signal 2013;25:615-629.

6 Siedlecka-Kroplewska K, Jozwik A, Boguslawski W, Wozniak M, Zauszkiewicz-Pawlak A, Spodnik JH, Rychlowski M, Kmiec Z: Pterostilbene induces accumulation of autophagic vacuoles followed by cell death in hl60 human leukemia cells. J Physiol Pharmacol 2013;64:545-556.

$7 \quad$ Nikhil K, Sharan S, Chakraborty A, Bodipati N, Krishna Peddinti R, Roy P: Role of isothiocyanate conjugate of pterostilbene on the inhibition of mcf-7 cell proliferation and tumor growth in ehrlich ascitic cell induced tumor bearing mice. Exp Cell Res 2014;320:311-328.

8 Lin VC, Tsai YC, Lin JN, Fan LL, Pan MH, Ho CT, Wu JY, Way TD: Activation of ampk by pterostilbene suppresses lipogenesis and cell-cycle progression in p53 positive and negative human prostate cancer cells. J Agric Food Chem 2012;60:6399-6407.

9 Cichocki M, Paluszczak J, Szaefer H, Piechowiak A, Rimando AM, Baer-Dubowska W: Pterostilbene is equally potent as resveratrol in inhibiting 12-o-tetradecanoylphorbol-13-acetate activated nfkappab, ap-1, cox-2, and inos in mouse epidermis. Mol Nutr Food Res 2008;52:S62-70.

10 Beck D, Niessner H, Smalley KS, Flaherty K, Paraiso KH, Busch C, Sinnberg T, Vasseur S, Iovanna JL, Driessen S, Stork B, Wesselborg S, Schaller M, Biedermann T, Bauer J, Lasithiotakis K, Weide B, Eberle J, Schittek B, Schadendorf D, Garbe C, Kulms D, Meier F: Vemurafenib potently induces endoplasmic reticulum stressmediated apoptosis in brafv600e melanoma cells. Sci Signal 2013;6:ra7.

11 Lakshmanan AP, Harima M, Suzuki K, Soetikno V, Nagata M, Nakamura T, Takahashi T, Sone H, Kawachi H, Watanabe K: The hyperglycemia stimulated myocardial endoplasmic reticulum (er) stress contributes to diabetic cardiomyopathy in the transgenic non-obese type 2 diabetic rats: A differential role of unfolded protein response (upr) signaling proteins. Int J Biochem Cell Biol 2013;45:438-447. 


\section{Cellular Physiology Cell Physiol Biochem 2016;38:1226-1244

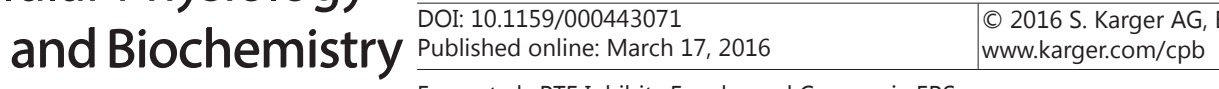

Feng et al.: PTE Inhibits Esophageal Cancer via ERS

12 Tay KH, Luan Q, Croft A, Jiang CC, Jin L, Zhang XD, Tseng HY: Sustained ire1 and atf6 signaling is important for survival of melanoma cells undergoing er stress. Cell Signal 2014;26:287-294.

13 Lee JH, Kwon EJ, Kim do H: Calumenin has a role in the alleviation of er stress in neonatal rat cardiomyocytes. Biochem Biophys Res Commun 2013;439:327-332.

14 Jin Z, El-Deiry WS: Overview of cell death signaling pathways. Cancer Biol Ther 2005;4:139-163.

15 Yu J, Zhang L: Apoptosis in human cancer cells. Curr Opin Oncol 2004;16:19-24.

16 Wang H, Yang Y, Chen H, Dan J, Cheng J, Guo S, Sun X, Wang W, Ai Y, Li S, Li Z, Peng L, Tian Z, Yang L, Wu J, Zhong X, Zhou Q, Wang P, Zhang Z, Cao W, Tian Y: The predominant pathway of apoptosis in thp-1 macrophage-derived foam cells induced by 5 -aminolevulinic acid-mediated sonodynamic therapy is the mitochondria-caspase pathway despite the participation of endoplasmic reticulum stress. Cell Physiol Biochem 2014;33:1789-1801.

17 Barille-Nion S, Bah N, Vequaud E, Juin P: Regulation of cancer cell survival by bcl2 family members upon prolonged mitotic arrest: Opportunities for anticancer therapy. Anticancer Res 2012;32:4225-4233.

18 Chow SE, Kao CH, Liu YT, Cheng ML, Yang YW, Huang YK, Hsu CC, Wang JS: Resveratrol induced er expansion and er caspase-mediated apoptosis in human nasopharyngeal carcinoma cells. Apoptosis 2014;19:527-541.

19 Galehdar Z, Swan P, Fuerth B, Callaghan SM, Park DS, Cregan SP: Neuronal apoptosis induced by endoplasmic reticulum stress is regulated by atf4-chop-mediated induction of the bcl-2 homology 3-only member puma. J Neurosci 2010;30:16938-16948.

20 Ghosh AP, Klocke BJ, Ballestas ME, Roth KA: Chop potentially co-operates with foxo3a in neuronal cells to regulate puma and bim expression in response to er stress. PLoS One 2012;7:e39586.

21 Wang FM, Galson DL, Roodman GD, Ouyang H: Resveratrol triggers the pro-apoptotic endoplasmic reticulum stress response and represses pro-survival xbp1 signaling in human multiple myeloma cells. Exp Hematol 2011;39:999-1006.

22 Yang Y, Wang J, Li Y, Fan C, Jiang S, Zhao L, Di S, Xin Z, Wang B, Wu G, Li X, Li Z, Gao X, Dong Y, Qu Y: Ho-1 signaling activation by pterostilbene treatment attenuates mitochondrial oxidative damage induced by cerebral ischemia reperfusion injury. Mol Neurobiol DOI:10.1007/s1203501591942.

23 Nawrocki ST, Carew JS, Pino MS, Highshaw RA, Dunner K Jr, Huang P, Abbruzzese JL, McConkey DJ: Bortezomib sensitizes pancreatic cancer cells to endoplasmic reticulum stress-mediated apoptosis. Cancer Res 2005;65:11658-11666.

24 Kong LM, Liao CG, Zhang Y, Xu J, Li Y, Huang W, Zhang Y, Bian H, Chen ZN: A regulatory loop involving mir22 , sp1, and c-myc modulates cd147 expression in breast cancer invasion and metastasis. Cancer Res 2014;74:3764-3778.

25 Li F, Jiang Z, Wang K, Guo J, Hu G, Sun L, Wang T, Tang X, He L, Yao J, Wen D, Qin X, Zhang L: Transactivation of the human nme5 gene by sp1 in pancreatic cancer cells. Gene 2012;503:200-207.

26 Anshu A, Thomas S, Agarwal P, Ibarra-Rivera TR, Pirrung MC, Schonthal AH: Novel proteasome-inhibitory syrbactin analogs inducing endoplasmic reticulum stress and apoptosis in hematological tumor cell lines. Biochem Pharmacol 2011;82:600-609.

27 Chou TC, Talalay P: Quantitative analysis of dose-effect relationships: The combined effects of multiple drugs or enzyme inhibitors. Adv Enzyme Regul 1984;22:27-55.

28 de Miranda Ramos V, Zanotto-Filho A, de Bittencourt Pasquali MA, Klafke K, Gasparotto J, Dunkley P, Gelain DP, Moreira JC: Nrf2 mediates neuroblastoma proliferation and resistance to retinoic acid cytotoxicity in a model of in vitro neuronal differentiation. Mol Neurobiol DOI:10.1007/s1203501595066.

29 Sung B, Park B, Yadav VR, Aggarwal BB: Celastrol, a triterpene, enhances trail-induced apoptosis through the down-regulation of cell survival proteins and up-regulation of death receptors. J Biol Chem 2010;285:11498-11507.

30 Guichard C, Pedruzzi E, Fay M, Marie JC, Braut-Boucher F, Daniel F, Grodet A, Gougerot-Pocidalo MA, Chastre E, Kotelevets L, Lizard G, Vandewalle A, Driss F, Ogier-Denis E: Dihydroxyphenylethanol induces apoptosis by activating serine/threonine protein phosphatase pp2a and promotes the endoplasmic reticulum stress response in human colon carcinoma cells. Carcinogenesis 2006;27:1812-1827.

31 Wang Y, Zhang J, Wang Q Zhang T, Yang Y, Yi Y, Gao G, Dong H, Zhu H, Li Y, Lin H, Tang H, Chen X: Bryostatin 5 induces apoptosis in acute monocytic leukemia cells by activating puma and caspases. Eur J Pharmacol 2013;718:340-349. 


\section{Cellular Physiology Cell Physiol Biochem 2016;38:1226-1244 \begin{tabular}{l|l}
\hline DOI: 10.1159/000443071 & (c) 2016 S. Karger AG, Basel
\end{tabular} www.karger.com/cpb \\ Feng et al.: PTE Inhibits Esophageal Cancer via ERS}

32 Pathi SS, Jutooru I, Chadalapaka G, Sreevalsan S, Anand S, Thatcher GR, Safe S: Gt-094, a no-nsaid, inhibits colon cancer cell growth by activation of a reactive oxygen species-microrna-27a: Zbtb10-specificity protein pathway. Mol Cancer Res 2011;9:195-202.

33 Jutooru I, Chadalapaka G, Abdelrahim M, Basha MR, Samudio I, Konopleva M, Andreeff M, Safe S: Methyl 2-cyano-3,12-dioxooleana-1,9-dien-28-oate decreases specificity protein transcription factors and inhibits pancreatic tumor growth: Role of microrna-27a. Mol Pharmacol 2010;78:226-236.

34 Papineni S, Chintharlapalli S, Abdelrahim M, Lee SO, Burghardt R, Abudayyeh A, Baker C, Herrera L, Safe S: Tolfenamic acid inhibits esophageal cancer through repression of specificity proteins and c-met. Carcinogenesis 2009;30:1193-1201.

35 Hedrick E, Crose L, Linardic CM, Safe S: Histone deacetylase inhibitors inhibit rhabdomyosarcoma by reactive oxygen species-dependent targeting of specificity protein transcription factors. Mol Cancer Ther 2015;14:2143-2153.

36 Chadalapaka G, Jutooru I, Safe S: Celastrol decreases specificity proteins (sp) and fibroblast growth factor receptor-3 (fgfr3) in bladder cancer cells. Carcinogenesis 2012;33:886-894.

37 Yeh CB, Hsieh MJ, Lin CW, Chiou HL, Lin PY, Chen TY, Yang SF: The antimetastatic effects of resveratrol on hepatocellular carcinoma through the downregulation of a metastasis-associated protease by sp-1 modulation. PLoS One 2013;8:e56661.

38 Choi AY, Choi JH, Hwang KY, Jeong YJ, Choe W, Yoon KS, Ha J, Kim SS, Youn JH, Yeo EJ, Kang I: Licochalcone a induces apoptosis through endoplasmic reticulum stress via a phospholipase $\mathrm{C} \gamma 1-, \mathrm{Ca}^{2+}$, and reactive oxygen species-dependent pathway in HepG2 human hepatocellular carcinoma cells. Apoptosis 2014;19:682-697.

39 Ma YC, Ke Y, Zi X, Zhao W, Shi XJ, Liu HM: Jaridonin, a novel ent-kaurene diterpenoid from isodon rubescens, inducing apoptosis via production of reactive oxygen species in esophageal cancer cells. Curr Cancer Drug Targets 2013;13:611-624.

40 Wu LF, Wei BL, Guo YT, Ye YQ, Li GP, Pu ZJ, Feng JL: Apoptosis induced by adenosine involves endoplasmic reticulum stress in ec109 cells. Int J Mol Med 2012;30:797-804.

41 Xu Y, Zhou L, Huang J, Liu F, Yu J, Zhan Q Zhang L, Zhao X: Role of smac in determining the chemotherapeutic response of esophageal squamous cell carcinoma. Clin Cancer Res 2011;17:5412-5422.

42 Kaufmann SH, Earnshaw WC: Induction of apoptosis by cancer chemotherapy. Exp Cell Res 2000;256:4249.

43 Rao RV, Castro-Obregon S, Frankowski H, Schuler M, Stoka V, del Rio G, Bredesen DE, Ellerby HM: Coupling endoplasmic reticulum stress to the cell death program. An apaf-1-independent intrinsic pathway. J Biol Chem 2002;277:21836-21842.

44 Jimbo A, Fujita E, Kouroku Y, Ohnishi J, Inohara N, Kuida K, Sakamaki K, Yonehara S, Momoi T: Er stress induces caspase-8 activation, stimulating cytochrome c release and caspase- 9 activation. Exp Cell Res 2003;283:156-166.

45 Ahmad IM, Aykin-Burns N, Sim JE, Walsh SA, Higashikubo R, Buettner GR, Venkataraman S, Mackey MA, Flanagan SW, Oberley LW, Spitz DR: Mitochondrial $\mathrm{O}_{2}{ }^{*}$ - and $\mathrm{H}_{2} \mathrm{O}_{2}$ mediate glucose deprivation-induced stress in human cancer cells. J Biol Chem 2005;280:4254-4263.

46 Mukhopadhyay P, Rajesh M, Hasko G, Hawkins BJ, Madesh M, Pacher P: Simultaneous detection of apoptosis and mitochondrial superoxide production in live cells by flow cytometry and confocal microscopy. Nat Protoc 2007;2:2295-2301. 